NBER WORKING PAPER SERIES

HEALTH SHOCKS, VILLAGE ELECTIONS, AND LONG-TERM INCOME: EVIDENCE FROM RURAL CHINA

\author{
Li Gan \\ Lixin Colin $\mathrm{Xu}$ \\ Yang Yao \\ Working Paper 12686 \\ http://www.nber.org/papers/w12686
}

\author{
NATIONAL BUREAU OF ECONOMIC RESEARCH \\ 1050 Massachusetts Avenue \\ Cambridge, MA 02138 \\ November 2006
}

We thank Martin Feldstein, Liutang Gong, Justin Lin, John Strauss, Zhixiong Zeng, and participants of seminars in the International Food Policy Research Institute, Nankai University, Peking University, Shanghai Jiaotong University, and the University of Wisconsin-Madison, for their helpful comments. Mengtao Gao, Shuna Wang, and Shenwei Zhang provided superb research assistance. The Research Center of Rural Economy, the Ministry of Agriculture, the People's Republic of China provided assistance in data collection. Financial supports from the Chinese Medical Board, the World Bank, and the National 211 Project of China are greatly appreciated. Corresponding author: Yang Yao, China Center for Economic Research, Peking University. Phone: 86-10-6275-3103; fax: 86-10-6275-1474; email: yyao@ccer.pku.edu.cn. The views expressed herein are those of the author(s) and do not necessarily reflect the views of the National Bureau of Economic Research.

(C) 2006 by Li Gan, Lixin Colin Xu, and Yang Yao. All rights reserved. Short sections of text, not to exceed two paragraphs, may be quoted without explicit permission provided that full credit, including (C) notice, is given to the source. 
Health Shocks, Village Elections, and Long-Term Income: Evidence from Rural China

Li Gan, Lixin Colin Xu, and Yang Yao

NBER Working Paper No. 12686

November 2006

JEL No. I12,O15,Z13

\begin{abstract}
$\underline{\text { ABSTRACT }}$
Using a sample of households in 48 Chinese villages for the period 1986-2002, this paper studies the dynamic effects of major health shocks on household income and the role played by village elections in mitigating these effects. Our results show that in the first 15 years after a shock, a shock-hit household on average falls short of its normal income trajectory by $11.8 \%$ and its recovery would take 19 years. Based on the premise that shock-hit families impose negative externalities on richer families by borrowing from them, our political economy model predicts that the outcome of village elections would differ from that of a standard median voter model in that the elected village leaders tend to adopt pro-poor policies. Our empirical study finds that villages are more likely to establish a healthcare plan after the election is introduced. In addition, village elections reduce the probability of a household to borrow by $16.7 \%$ when one of its working adults is seriously sick. As a result, they reduce more than half of the negative effect of a health shock on household income.

Li Gan

Department of Economics

Texas A\&M University

905 Plainfield $\mathrm{Ct}$

College Station, TX 77845

and NBER

gan@econmail.tamu.edu

Lixin Colin $\mathrm{Xu}$

MC 3-420, World Bank

1818 H Street, N.W.

Washington, DC 20433

lxu1@worldbank.org

Yang Yao

China Center for Economic Research

Peking University

Peking, China

yyao@ccer.pku.edu.cn
\end{abstract}




\title{
HeAlth Shocks, Village Elections, AND LONG-TERm INCOME: EVIDENCE FROM RURAL CHINA
}

\begin{abstract}
Using a sample of households in 48 Chinese villages for the period 1986-2002, this paper studies the dynamic effects of major health shocks on household income and the role played by village elections in mitigating these effects. Our results show that in the first 15 years after a shock, a shock-hit household on average falls short of its normal income trajectory by $11.8 \%$ and its recovery would take 19 years. Based on the premise that shock-hit families impose negative externalities on richer families by borrowing from them, our political economy model predicts that the outcome of village elections would differ from that of a standard median voter model in that the elected village leaders tend to adopt pro-poor policies. Our empirical study finds that villages are more likely to establish a healthcare plan after the election is introduced. In addition, village elections reduce the probability of a household to borrow by $16.7 \%$ when one of its working adults is seriously sick. As a result, they reduce more than half of the negative effect of a health shock on household income.
\end{abstract}

JEL classification: I12, O15, Z13

Keywords: health shocks, village governance, farmers’ income. 


\section{HeAlth SHOCKS, ViLlage Elections, AND LONG-TERM INCOME: EVIDENCE FROM RURAL CHINA}

Major health shocks have a direct effect and an indirect effect for uninsured or partially insured farm households in terms of their long-term income. The direct effect is that the family loses income for a period of time if the sick person is a major laborer in the family. The indirect effect is related to the treatment of the illness. The family has to spend a large amount of money in a short period of time, which often leads to heavy indebtedness. This forces the family to slow down its pace of asset accumulation including children's education. As a result, this family loses or partially loses its capability to generate income in the long run. Adding together, these two effects may cause a household struck by a major health shock to fall into persistent poverty.

Despite the possible dire effects of health shocks, systematic studies have been sparse to determine the extent and duration of the above negative impacts, primarily because of the lack of properly designed longitudinal data (Foster, 1995; Strauss and Thomas, 1998). Using a unique longitudinal dataset of 17 years from rural China, the first goal of this paper is to provide an assessment of the impacts of major health shocks on farmers' long-term income. Our strategy is to first build up a heuristic dynamic model and obtain a testable hypothesis regarding the negative impacts of health shocks, and then to test the hypothesis using our dataset. The distinct feature of the hypothesis is that a family's income trajectory after a health shock follows a 
U-shaped path over time relative to its income trajectory on the balanced growth path. This is so because a shock-hit family's physical and health capital accumulation is crowded out by the treatment of the illness in the first several years after a shock, but then gradually picks up in later years.

During our sample period (1986-2002), an important institutional change occurred in China. Democratic elections at village level were first experimented in the mid-1980s and later in 1998 a formal law --- The Organic Law for the Village Committee (OLVC) --- was enacted that requires all villages to hold elections. Despite many controversies and political fights, elections have spread to every corner of the country and taken roots in the grassroots society (O’Brien and Li, 2000). Local elections have been found to increase the accountability of the local government in recent literature. Zhang, Fan, Zhang, and Huang (2004) and Wang and Yao (2006) find that elections have shifted government spending from items benefiting the village leaders to those benefiting the general public in Chinese villages. While these findings are largely consistent with predictions of the standard median voter model, there are findings showing that the outcomes of village elections could depart from the predictions of the model under the assumption of a symmetric population. For instance, Shen and Yao (2006) find that elections have brought about more equal income distribution in Chinese villages. Foster and Rosenzweig (2001) find that village elections in India lead local governments to spend more on road building instead of on irrigation facilities. Road building provides jobs to the landless, who are 
only minority in rural Indian, ${ }^{1}$ so elections lead to a pro-poor policy. Chattopadhyay and Duflo (2004) find that elected female village heads in India tend to adopt more women-friendly policies, which implies that personal preferences of the elected officials can lead to outcomes that deviate from the predictions of the median voter model.

In this paper, we propose and test another channel for the outcomes of local elections to deviate from the median voter model based on the premise that health shocks not only hurt the families receiving them, but also bring negative externalities to other families. We set our stage in the case of establishing self-financed healthcare plans in a village. The tradeoff for a family is between the amount of income it could recover from the plan and the premium it has to pay. To the extent that health shocks bring a smaller loss to richer families than to poorer families, richer families subsidize poorer families in a healthcare plan. When health shocks do not bring negative externalities, the elected village leader does not have an incentive to establish a healthcare plan in a village with a symmetric distribution of income (or wealth) because the median voter has a net gain of zero and thus is indifferent with such a plan. However, when health shocks bring negative externalities, the outcome may change. The key is that after receiving a major health shock, poorer families have to rely on private social networks to deal with the shock. They would most likely to borrow from richer relatives or friends who are bound by social ties not to reject. This then imposes a negative externality on richer villagers. The median voter then has a

\footnotetext{
${ }^{1}$ Landless households in rural India are about $11 \%$ of the total number of rural households. See Srivastava, Saxena, and Thorat (forthcoming).
} 
positive net gain from a healthcare plan that fully insures against the income loss brought by a major illness because the plan not only compensates for his direct expected loss due to the illness, but also eliminates the expected loss imposed by farmers poorer than he is. Therefore, villages with elections are more likely to establish a healthcare plan. As a result, families in villages with elections are in a better position to deal with health shocks, so their long-term income should be higher. The second goal of this paper then is to study if village elections lead to a better chance for a village to establish a healthcare plan, to reduce shock-hit families' needs to borrow from informal sources, and ultimately to mitigate the negative impacts of health shocks on farms' long-term income.

Our data come from two major sources. One is the National Fixed-point Survey (NFS) maintained by the Research Center of Rural Economy, the Ministry of Agriculture, the People’s Republic of China. It provides background village information for the period 1986-2002 and household information for the period 1987-2002. The second data source is a retrospective survey conducted by the authors in the spring of 2003 to obtain information on the household history of major illnesses and village governance in the period of 1986-2002. The assembled dataset enables us to study the dynamic impacts of major health shocks on households' long-term income trajectories and elections' role in mitigating these impacts.

We show that a household with a major health shock on average falls short of its normal income trajectory by $11.6 \%$ within 15 years after the shock. The peak of the negative impact happens in the $8^{\text {th }}$ year after the shock when the income shortfall 
reaches $28.4 \%$. Extrapolating our estimates beyond the $15^{\text {th }}$ year, the longest duration that our data allow us to study, we find that it would take 19 years for a shock-hit household to fully recover to its normal income trajectory.

Village elections are found to play a significant role in mitigating the negative impacts of major health shocks. Having elections raises a village’s probability to have a healthcare plan by $11.6 \%$ and reduces the probability of a household to borrow by 9.9\% when one of its working adults is seriously sick. On average, elections move a shock-hit household closer to its normal income trajectory by about half of the average negative effect of a shock.

One potential problem for our results is the selection biases in illness reporting. Since we had to resort to a somewhat arbitrary definition of a major health shock --- it is qualified as a major health shock if a treatment required an expenditure of more than 5,000 RMB (about 633 dollars) or hospitalization, it is likely that the reports of the shocks were correlated with income and other family characteristics. It is ideal to handle this problem by using individual or household level instruments for the shock, but such instruments are hard to find. Instead, we follow the literature (e.g., Strauss and Thomas, 1998) by using two community-level variables, the number of hospitals in the township/xiang and the number of hospitals in the county, as the instruments for the shocks. Our two-stage panel estimation qualitatively confirms our earlier results.

Another potential problem is the endogeneity of the introduction of village elections. Although the province was the key in spreading village elections, variations within a province existed. The characteristics of the residents could play a role in 
determining whether a village started elections. We instrument the introduction of village elections by the timing of a province's adoption of the OLVC and two village-level variables reflecting the distribution of lineages. The new results are consistent with our earlier results except in the case of village healthcare plans.

The rest of the paper is arranged as the follows. Section 1 first presents a simple dynamic model for the U-shaped impacts of a health shock on farmers' long-term income, and then constructs a simple political economy model to show how the negative externalities of health shocks could lead to the establishment of a healthcare plan. Section 2 introduces the data and discusses some measurement issues. Section 3 tests our hypotheses regarding the negative impacts of health shocks on household income. Section 4 studies the role of village elections in mitigating the negative impacts of health shocks. Section 5 concludes.

\section{The Theoretical Model}

There are several ways to model a health shock. One way is to assume that the probability that an individual experiences a health shock depends on previous health expenditures. Here we adopt a simpler way of modeling the health shock by assuming that the probability of a health shock does not depend on previous decisions of the individual. As a consequence of this assumption, the household behaves before the health shock arrives as if the shock would never arrive. This assumption is common in the literature on natural shocks (e.g., Jacoby and Skoufias, 1996). A potentially important problem, however, is that it assumes away households' preventative 
measures against health shocks. To remedy this problem, we will make the size of the shock endogenously determined by the stock of health when a shock arrives. Since our concern is the impacts of large health shocks, modeling the size of the shock is a reasonable approach.

\subsection{The balanced growth path of a shock-free farmer}

We first develop the benchmark case in which a household never receives a health shock in its lifetime. To simplify the exposure, we model an individual farmer instead of a household. The representative farmer starts with an initial stock of physical assets $K_{0}$ and an initial stock of health $H_{0}$. Here physical assets include productive equipment and bank deposits while health can be thought as the level of effective labor supply. The farmer's production technology exhibits constant return to scale in physical assets and health stock, and the production function is $y_{t}=A K_{t}^{\alpha} H_{t}^{1-\alpha}, \alpha \in(0$, 1), where $K_{t}$ and $H_{t}$ are his stocks of assets and health at the beginning of year $t$, and $A$ is an efficiency index that can be influenced by both the farmer's own ability and the village's public supports. The farmer's consumption in period $t$ is $c_{t}$, and his utility derived from consumption is $\ln \left(c_{t}\right)$. In each period, the farmer decides his levels of consumption $c_{t}$, investment in assets $I_{t}$, and investment in health $e_{t}$. Asset and health stocks evolve as follows:

(1) $K_{t+1}=K_{t}+I_{t}-\delta K_{t}$, and

(2) $H_{t+1}=H_{t}+h e_{t}-\sigma H_{t}$.

In (1), the assets follow the usual evolvement with a depreciation rate of $\delta$. Following 
Grossman's seminal papers (Grossman, 1972, 1973) on health stock, we let the health stock have the same motion of evolvement: during each period, health stock $H_{t}$ depreciates at the rate of $\sigma$. An investment (health expenditure) of $e_{t}$ would raise the health stock by $h \cdot e_{t}$, where $h$ is the conversion factor between the health stock and health investment.

A salient feature of low-income economies is that farm households are credit constrained. Here we assume the extreme case in which the representative farmer has to rely on its current income to finance his consumption and investments in both physical assets and health. With the above setup, the representative farmer's problem in any year $t$ is

$$
\begin{array}{ll}
\underset{c_{t}, I_{t}, e_{t}}{\operatorname{aax}} \ln c_{t}+\rho V_{t+1}\left(K_{t+1}, H_{t+1}\right) \\
\text { s.t. } & c_{t}+I_{t}+e_{t}=A K_{t}^{\alpha} H_{t}^{1-\alpha} \\
& K_{t+1}=K_{t}+I_{t}-\delta K_{t}, \\
& H_{t+1}=H_{t}+h e_{t}-\sigma H_{t}, \\
& I_{t}, e_{t} \geq 0,
\end{array}
$$

where $\rho$ is the discount factor, and $V_{t+1}$ is the farmer's value function starting in period $t+1$. Abstract from its contents, this is a standard Ramsey-type growth model and has a unique balanced growth path (BGP). Appendix I shows the details of the solution process. Assuming that assets and health have the same depreciation rate, that is, $\delta=\sigma$, then we have on the BGP

(4) $\frac{C_{t+1}}{C_{t}}=\rho\left[(1-\alpha)^{1-\alpha} \alpha^{\alpha} h^{1-\alpha} A+(1-\delta)\right]$, and

(5) $\frac{K_{t}}{H_{t}}=\frac{\alpha}{(1-\alpha) h}$.

A corollary of equation (5) is that given the same production technology of constant 
return to scale, all the farmers have the same marginal product of assets at the BGP regardless of the levels of their stocks of assets and health. It also follows from the above two equations that

(6) $\frac{y_{t+1}}{y_{t}}=\frac{K_{t+1}}{K_{t}}=\frac{H_{t+1}}{H_{t}}=\frac{C_{t+1}}{C_{t}}$.

That is, income, assets, and health grow at the same constant rate that the consumption is growing with. It is noteworthy that this rate increases in $A$. To the extent that they increase $A$, village public supports increase farmers' income, asset, and health growth rate at the BGP. Holding the initial levels constant, this means that village public supports also bring farmers to a BGP with higher levels of income and stocks of assets and health.

\subsection{Health shocks and the borrower}

We assume that the representative farmer has already been on the BGP when the health shock arrives. We also make the assumption that the shock always arrives at the beginning of a year and the farmer will only receive one shock in his lifetime. The severity of the shock negatively depends on the farmer's stock of health when the shock arrives. So, assuming that he receives the shock in year $\tau$, his health stock after the shock becomes

(7) $\tilde{H}_{\tau}=H_{\tau}-L\left(H_{\tau}\right)$, where $L($.$) is an decreasing function of H_{\tau}$ and is between 0 and $H_{\tau}$ for any $\tau$. We assume that the treatment of the health shock happens immediately after the shock, so does the expenditures. With the treatment, the farmer's health does not deteriorate to 
fall below $\tilde{H}_{\tau}$. The expenditure $E$ to cure the illness increases in $L\left(H_{\tau}\right)$ so we express it as a decreasing function of $H_{\tau}, E\left(H_{\tau}\right)$. The farmer has to sell his assets to pay for $E .^{2}$ Let the amount of his sales be $K_{E}$, so the stock of assets left with him is

(8) $\tilde{K}_{\tau}=K_{\tau}-K_{E}$.

$K_{E}$ may not be enough to pay for $E$ in which case the farmer borrows

(9) $B=E\left(H_{\tau}\right)-K_{E}$

from relatives or friends within the village. If $B$ is positive, we call the farmer a

borrower. It is worth keeping in mind that $B$ changes as $\tau$ changes. The annual interest rate is exogenously given as $r$. Since farmers are credit constrained, $r$ is smaller than the marginal product of assets on the BGP for everyone. The term of the debt is fixed to $T$ years. Assuming that he starts to repay the debt in period $\tau$ with equal payment for each year, the borrower needs to repay $b=(0.5+1 / T) r+B / T$ in each period.

At the beginning of year $\tau$, therefore, a shock-hit farmer needs to determine the amount of assets to cash in and the paths for subsequent asset and health accumulation. Conditional on the first decision's having been made, the second set of decisions can be expressed as

$$
\begin{aligned}
\text { (10) } \underset{c_{t}, I_{t}, e_{t}}{\operatorname{Max}} & \sum_{t=\tau}^{t=\tau+T-1} \rho^{t-\tau} \ln c_{t}+\rho^{T} V_{\tau+T}\left(K_{\tau+T}, H_{\tau+T}\right) \\
\text { s.t. } & c_{t}+I_{t}+e_{t}=A K_{t}^{\alpha} H_{t}^{1-\alpha}-b, \text { for } \tau \leq t \leq \tau+T \\
& c_{t}+I_{t}+e_{t}=A K_{t}^{\alpha} H_{t}^{1-\alpha}, \quad \text { for } t>\tau+T \\
& K_{t+1}=K_{t}+I_{t}-\delta K_{t}, \\
& H_{t+1}=H_{t}+h e_{t}-\sigma H_{t}, \\
& I_{t}, e_{t} \geq 0 .
\end{aligned}
$$

\footnotetext{
${ }^{2}$ We have defined assets as productive equipment and bank deposits, and deliberately excluded durable consumption goods such as houses because the secondary markets for these goods are very thin in rural China.
} 
Denote the value function of the problem in (10) by $V_{\tau}\left(B, \tilde{K}_{\tau}, \tilde{H}_{\tau}\right) . \tilde{H}_{\tau}$ is predetermined by the shock and $H_{\tau}$, so we only need to study the farmer's decision on the size of the borrowing, the other decision that we laid out for him at the beginning of year $\tau$. This is equivalent to determining $\tilde{K}_{\tau}$ and $K_{E}$ by solving the following problem:

$$
\begin{aligned}
\text { (11) } \operatorname{Max}_{\widetilde{K}_{\tau}, K_{E}} & V_{\tau}\left(B, \tilde{K}_{\tau}, \tilde{H}_{\tau}\right) \\
\text { s.t. } & B=E\left(H_{\tau}\right)-K_{E}, \\
& K_{E}+\tilde{K}_{\tau}=K_{\tau} .
\end{aligned}
$$

Appendix II establishes the following intuitive and useful result:

Result 1. A farmer who has a larger stock of physical assets at the time when a health shock occurs tends to borrow less.

The BGP of the problem in (10) is the same as that in (3). But we are more interested in its transition dynamics. Analytical results are impossible, though; so we rely on numerical simulations to assess the transition dynamics. Figure 1 presents the results of one set of the simulations. Chart A compares the income trajectory after the shock and the one on the BGP, and Chart B shows the gap between the two trajectories. The shock is assumed to be large, knocking down income by about $30 \%$ in the first year. The gap then follows a U curve with the trough happening in the $11^{\text {th }}$ year after the shock happens. The figure ends at the $27^{\text {th }}$ year after the shock and shows that the gap is still large at that point. The intuition behind the $U$ curve is relatively straightforward. A shock-hit farmer loses his health and needs to cash in his physical assets to pay for his treatment, so his income immediately declines. The decline may continue even after he finishes repaying his debts (in Figure 1, the 
repayment period is set to 5 years) because he can not invest much at the low level of income so his stock of assets declines because of depreciation. It is only after his stocks of both health and assets begin to increase again will his income increase. So we have the following testable hypothesis:

Hypothesis 1. The income of a shock-hit farmer falls below his BGP level and follows a U-shaped trajectory relative to his BGP.

[Figure 1 about here]

\subsection{Health shocks and the lender}

When a farmer who has experienced a health shock approaches a lender, the lender is often obligated to lend by the social norms in small-village settings. Since a health shock cannot be anticipated by either the borrower or the lender, the lender's asset and health accumulation path is likely to be changed. The loan is not the same as an ordinary loan. It is an unexpected event, and the lender has to sell off his assets to make the loan. As a result, the loan is likely to reduce the lender's overall welfare.

Assume that the lender is on the BGP when he is approached by a shock-hit farmer in year $\tau$ and it is already optimal for the lender not to lend. ${ }^{3}$ Because of social obligations, he has to make a loan of the amount $B$ to the borrower. Then he gets back $b$ in each period for $T$ periods. The following arguments establish that the lender loses with the lending. First, the lending forces the lender to operate with a stock of assets that is below its BGP level. Second, the lending is equivalent to the case in which the

\footnotetext{
${ }^{3}$ This second assumption is not essential, though. Even if the lender does lend on the BGP, the loan to the borrower is still an unexpected event and reduces the lender's asset stock to the level below its optimum.
} 
lender rents out assets in the amount of $B, B-b, B-2 b, \ldots, b$ in the years between $\tau$ and $\tau+T-1$, respectively, that all bring a constant rate of return of $r$. Third, the marginal product of assets in each period is larger than that on the BGP because the stock of assets is smaller. Since $r$ is less than the marginal product of assets on the BGP, it is better for the lender to use the assets lent out in his own production.

\subsection{The role of village elections}

Before village elections were introduced, the village government in rural China was appointed by the township government so its main mandate was to meet the demands of the upper-level governments. With village elections, the village government has to care about the demands of the majority of the villagers if it wants to be reelected. The most convenient model to study the outcome of a democracy is the median voter model, which we adopt here. In the case of no externalities, the median voter is indifferent with a pro-poor policy, so such a policy is not guaranteed by voting. In our case, a shock-hit farmer borrows from richer farmers and imposes negative externalities on them. Since the incidence of health shocks is random, almost everyone in the village would have a chance to receive the negative externalities. The village government can then establish an insurance scheme with a reasonable coverage (to be exactly defined shortly) and wins the support of the median voter.

To begin with our formal modeling, it is natural to set the political stage on the BGP. Result 1 establishes that the amount of borrowing of a shock-hit farmer depends on his stock of physical assets at the time when a shock arrives. So we will work with 
the distribution of the stock of assets on the BGP. ${ }^{4}$ Assume that in any period $\tau$ the stock of physical assets is distributed symmetrically in the interval $[\underline{K}, \bar{K}]$ with the mean and median being $K_{E}$ (the subscription $\tau$ is suppressed). Let $\phi(K)$ and $\Phi(K)$ denote the density and accumulative function of the distribution, respectively. Let $p$ be the probability that a particular farmer is hit by a health shock. For any farmer with a stock of assets $K$, his direct expected loss due to a health shock, denoted by $C_{B}(K)$, is the discounted sum of the his income losses:

$$
C_{B}(K)=p \sum_{t=\tau}^{t=\infty}\left[y_{t}^{b}(K)-y_{t}^{s}(K)\right]\left(\frac{1}{1+r}\right)^{t-\tau}
$$

where $y_{t}^{b}(K)=A K^{\alpha} H^{1-\alpha}$ and $y_{t}^{s}(K)=A \tilde{K}^{\alpha} \tilde{H}^{1-\alpha}$ are his income at the BGP and the transitional path, respectively, with $\widetilde{K}$ and $\tilde{H}$ being defined in (8) and (7), respectively. It is evident that $C_{B}(K)$ is positive by Hypothesis 1 . In addition, it decreases in $K$ because of Result 1 and the diminishing marginal product of assets.

In addition to the direct loss, a farmer also incurs a loss from the negative externalities that the shock-hit farmers imposed on him. To be consistent with our initial idea, we assume that a shock-hit farmer with a stock of assets $x$ borrows from one of the farmers who have a stock of assets larger than $x$. So the density function for a farmer with a stock of capital $K>x$ to be forced to lend is $\phi(K) /[1-\Phi(x)]$. Let $L(x$, $K$ ) denote farmer $K$ 's discounted value of loss caused by the borrowing of farmer $x$ (to abuse a bit notions, we use the stock of assets to denote farmers). It is value is

$$
L(x, K)=\sum_{t=\tau}^{t=\tau+T-1}\left[f_{K}^{\prime}\left(K_{t}(K), H_{t}(K)\right)-r\right][B(x)-(t-\tau) b]\left(\frac{1}{1+r}\right)^{t-\tau}
$$

\footnotetext{
${ }^{4}$ The other state variable, the stock of health, is proportional to the stock of physical anyway.
} 
where $B(x)$ is farmer $x$ 's borrowing. By the results of the last two sub-sections, $L(x ; K)$ is positive and decreases in both $x$ and $K$. The expected loss of farmer $K$, which we denote by $C_{L}(K)$, is the sum of the costs imposed by all the farmers who have a stock of assets less than his:

(14) $C_{L}(K)=\int_{\underline{K}}^{\bar{K}} p \frac{\phi(K)}{1-\Phi(x)} L(x, K) d x$.

The relationship between $C_{L}(K)$ and $K$ is complicated. In Figure 2 we show one plausible scenario in which $C_{L}(K)$ first increases in $K$ and then turns flat afterwards. ${ }^{5}$ The shape of $C_{L}(K)$ is not important for our discussion, though. What is important is that $C_{L}(K)$ is positive for everyone.

[Figure 2 about here]

To discuss how the negative externalities would change villagers’ voting behavior, we consider a simple case in which $C_{B}(K)$ is linear in $K$, as shown in Figure 2. Then let us think about an insurance scheme that aims at insuring against the direct cost of health shocks. ${ }^{6}$ It is straightforward to show that charging a risk premium that is equal to $C_{B}\left(K_{m}\right)$, the direct loss of the median voter, suffices to provide full insurance for all because the surplus of the richer portion of the population (the shaded triangle

\footnotetext{
${ }^{5}$ The intuition is the following. First of all, a farmer will be asked by more people to lend when his stock of assets is larger, so his total loss increases with his stock of assets. On the other hand, however, the loss brought about by one lending diminishes when a farmer is better endowed with assets. In addition, to the extent that the density of farmers decreases with the stock of assets, a farmer's chances to be approached by one shock-hit farmer diminish as his stock of assets increases.

${ }^{6}$ This scheme is different from most of the insurance schemes in practice, which insure against the cost of treatment. We work with the income loss for the purpose to simplify our analysis. It is noteworthy that insuring against income losses is more demanding than insuring against the treatment cost, so our results are robust.
} 
on the right) just compensates the deficit of the poorer portion of the population (the shaded triangle on the left). However, in the case without negative externalities, this insurance scheme will not be approved by the constituency because the median voter is indifferent with it. In the case with negative externalities, the scheme will win the support of median voter because it eliminates his burden of the indirect cost imposed by the borrowings of farmers that are poorer than he is. This establishes our second testable hypothesis:

Hypothesis 2. A village with elections is more likely to establish a healthcare plan than a village without.

Based on this hypothesis and our earlier results, we have two more testable hypotheses:

Hypothesis 3. A shock-hit person living in a village with elections borrows less than another living in a village without elections.

Hypothesis 4. Election reduces the negative impacts of a health shock on income.

Hypothesis 3 directly follows Hypothesis 2 because a healthcare plan substitutes for own spending. Hypothesis 4 follows Hypothesis 3. Elections reduce a shock-hit farmer's borrowings so his accumulation of assets is less affected by the shock, and his income can recover quicker to his BGP level.

\section{Data and Measurements}

\subsection{Data}


As mentioned in Section 1, two major data sources are used in this analysis. One is the National Fixed-Point Survey (NFS), and the other is a retrospective survey conducted by the authors in 2003. The NFS started in 1986 and is a longitudinal survey of about 34,000 households in all continental Chinese provinces. It used a stratified random sampling strategy to draw its sample when it was first started. Despite attritions, it has generally maintained a panel structure although mis-numbering of households exists. Because of the budget constraint of our research fund, the retrospective survey was only conducted in a sub-sample of the full NFS sample. In particular, we randomly select 48 villages in 8 provinces to conduct the retrospective survey. The eight provinces are Guangdong, Zhejiang, Hunan, Henan, Shanxi, Jilin, Sichuan, and Gansu. They are representative of the various regions in China.

To ensure a panel structure for the data, we used several combined criteria based on household characteristics (the size of the house, landholding, number of people, and the age of the head) to identify and match households. Consequently, in the eight provinces covered by our survey, 1,354 households remained in the sample. The exclusion is likely to be random as no systematic attrition and change of households were reported in the NFS. As a result, our samples can be treated as a stratified random sample. The NFS has already provided information on village and household economic and social characteristics, so our supplemental survey only asked questions related to individual health history and village governance. The household data provided by the NFS cover the period 1987 to 2002, but do not have information for 
1990, 1992, and 1994 when no surveys were conducted because of budgetary problems. The village data provided by the NFS cover one more year of 1986 . We input the missing village data of the three years by the average of the nearby two years but leave the household data intact.

The 2003 retrospective survey asked three sets of information. The first set is concerned with the family history of major illnesses since 1986. Key questions were asked for information on when an illness happened, how serious it was, personal data of the patient, and whether loans were taken for its treatment. The second set is about village elections since 1986. Key questions were asked about the frequency of the election and the nomination procedure and composition of the elected village committee in each election. The third set is about the healthcare services and facilities in the villages since 1986 including information on healthcare plans, clinics, and village subsidies to health services and facilities. Later, a phone interview also retrieved information on village lineages and the numbers of hospitals in the township and the county.

In summary, we have complete household-level data for 13 years (1987-2002, with data of 1990, 1992, and 1994 missing) and complete village-level data for 17 years (1986-2002). This long panel of data allows us to estimate the impact of health shocks and the role of elections in mitigating it.

Figure 3 presents the trend of income growth in the sample. Income growth was substantial over the period of 1987-2002. The average per-capita income in 2002 was 
2.2 times of that in $1987,{ }^{7}$ which implies an average annual growth rate of $5.4 \%$.

[Figure 3 about here]

\subsection{Measurement issues}

In our supplemental survey, we define a major health shock as an illness that requires hospitalization or a total spending over 5,000 RMB for practical reasons. The period covered by our survey is very long, so we had to restrict our attention to major health shocks so as to ensure the accuracy of people's recounting of their families' health history. However, this definition causes a truncation on the incidence of illness. Some households may have experienced a major health shock but nevertheless neither spent more than 5,000 RMB nor sent the patient to hospital because they did not have enough money. This truncation thus may systematically exclude poor families who experienced major health shocks.

To find out if our definition of health shocks causes under-reporting from poorer households, we compare in Figure 4 two income series, one is the average annual income of the households who reported no health shocks in the survey period, and the other is the average annual income of those who reported at least one health shock. In the figure and our subsequent analysis, a household is classified as being hit by a health shock if one of his members was hit by a major health shock. ${ }^{8}$ The two income

\footnotetext{
${ }^{7}$ The average income in our sample was higher than the national average of 2,476 RMB in 2002. NFS relies on household bookkeeping to collect data, so it oversamples larger and better-educated households when it first started in 1986 because these households were more able to maintain good bookkeeping.

${ }^{8}$ Some households were hit twice in the survey period. Those households start to be classified as being hit by a
} 
series followed almost identical trajectories. Averaging over the entire period of 1987-2002, the shock-hit households had a slightly lower per-capita income than the shock-free households (-10.64 RMB on average), but the gap was highly insignificant on statistical measures. Therefore, report biases based on cross-sectional income gaps are not likely to be a serious problem in the data.

[Figure 4 about here]

However, Figure 5 shows that there is a significant up-trend in illness reports over time. The incidence of shocks increased from the range of $2 \%$ to $5 \%$ in the early years to the range of around $10 \%$ in 2001 and 2002. One explanation for this large increase is income growth over the time period. However, other explanations are also possible. For example, memory loss may cause a smaller number of reports for the earlier years. In addition, the people in our sample became significantly older in our sample period; their average age increased from 26.3 years old in 1987 to 37.7 years old in 2002. So the incidence of illness naturally rose over the years. It is thus possible that the trend displayed in Figure 4 reflects a real phenomenon rather than report biases.

[Figure 5 about here]

It is noteworthy, though, that the existence of truncation will only reinforce our results if we find that health shocks reduce a household's long-term income because truncation selects more high-income households into the group of shock-hit households. Therefore, the estimate of our upcoming econometric exercise can serve as the lower bound for the negative effect of health shocks. Nevertheless, two 
alternative specifications, one using a sub-sample of the early years when illness reports are more homogenous, and one using instruments for the incidence of health shocks, are estimated to check the robustness of our results.

\section{Negative Impacts of Health Shocks}

\subsection{Econometric models and variables}

To study the negative effects of health shocks on income, we first estimate the following baseline panel model with household and year fixed effects:

(15) $\ln y_{i t}=X_{i t} \beta+\alpha_{s} S_{i t}+\alpha_{i}+\alpha_{t}+e_{i t}$, where $y_{i t}$ is the per-capita income (in $2002 \mathrm{RMB}$ ) of household $i$ in year $t, X_{i t}$ is a set of control variables; $S_{i t}$ is a dummy variable indicating whether a household is hit by a health shock, that is, it takes value 1 since a household is hit and takes value 0 before it is hit; $\alpha_{i}$ is the household fixed effect, $\alpha_{t}$ is the year fixed effect, and $e_{i t}$ is an i.i.d. error term. The control variables in $X_{i t}$ are household size, average age of household members and its square, dependent ratios (the ratios of children less than 16 years old and elders over 60 years old in total number of household members), per-capita landholding (in $m u$, which is equal to one fifteenth hectare), and years in school of the household head. The square of the average household age is included to capture the life-cycle effect in a household's income capability. In rural China, land is allocated by the village and the distribution is adjusted periodically to roughly equalize the per-capita landholding in each household (Liu, Carter, and Yao, 1998). So per-capita landholding can be regarded as independent of the income. The educational 
attainment of the household head is not likely to be affected by the current income because the head obtained his/her education before the family was formed. However, it is possible that the household's demographic characteristics are correlated with income. For example, low-income households may have more children due to the substitution between quality and quantity (Becker, Murphy, and Tamura, 1990). Allowing household fixed effect may mitigate this type of endogeneity since the fixed-effect model permits arbitrary correlation between the fixed effect term $\alpha_{i}$ and the regressors, including all demographic variables. Nevertheless, we will estimate equation (15) without the demographic variables to see how our results would differ. After deleting observations with missing data, we are left with 1,185 households with a total of 13,515 observations for the period of 1987-2002 (with data of 1990, 1992, and 1994 missing). Basic statistics of the control variables as well as those of the dependent variables are provided in Table 1.

[Table 1 about here]

The two-way fixed-effect model in (15) provides an almost ideal control on the endogeneity of health shocks that arises from missing variables that are not time variant. However, it may not control the endogeneity arising from the kind of reverse causality that we described in the last section. To take care of this problem, we follow the literature to use two community variables to instrument health shocks. They are the number of hospitals in the township or xiang that the village resides and the number of hospitals in the whole county. More hospitals increase competition and make it more convenient for families to send their sick members to hospitals. Both 
work to reduce the costs of hospitalization, so households residing in a region with more hospitals will be more likely to treat their sick members. On the other hand, more hospitals do not have an impact on household income except through the channel of health. Therefore, the two instruments are reasonable ones for our purpose.

Another way to check our results is to estimate equation (15) only with the observations of the early years. Figure 5 shows that up to 1996, the incidence of health shocks was about 3-4\% each year. So as a robustness check we will estimate the model again by using the observations of $1987-1996 .^{9}$

\subsection{Average effects of health shocks}

[Table 2 about here]

Table 2 presents the results of the above estimations. Column (1) presents the results of the baseline model in (15). It shows that a health shock reduces household per-capita income by an average of $11.9 \%$ in each year after the shock at the $1 \%$ significance level. Given that a household has already spent at least 5,000 RMB for the shock, the negative welfare impact of a major health shock on households is striking.

All the control variables except the schooling years of the household head have significant coefficients. As expected, household size and dependent ratio reduce per-capita income, and more land increases per-capita income. In addition, there is an

\footnotetext{
${ }^{9}$ There could be a problem of memory loss. However, there is no a prior reason to believe that richer households are less likely than poor households to remember major health shocks.
} 
inverse U relationship between average household age and per-capita income, which is consistent with the life-cycle behavior of the family.

Column (2) in Table 2 presents the results when the demographic variables are dropped. The negative effect of a health shock is only slightly higher than in Column (1). So the endogeneity of the demographic variables is not likely to bias the coefficient of the health shock, the main concern of this paper.

Column (3) repeats Column (1) using data of period 1987-1996. The results are qualitatively the same as those of Column (1) except that the inverse U relationship between household age and income vanishes. In particular, the negative impact of a health shock is to reduce per-capita income by $13.5 \%$, which is larger than but still close to the impact found in Column (1). To the extent that report biases were less likely to happen in the early years, this result is consistent with our conjecture that our estimation in Column (1) using the whole sample would provide the estimate of the lower bound of the impact of health shocks.

The conclusion that a major health shock has a very large effect on long term income is also supported by the results of the two-stage estimation reported in Column (4) of Table 2. ${ }^{10}$ These results are qualitatively the same as those of Column (1). In particular, the coefficient of the health shock dummy remains significantly negative. Its magnitude, however, has become substantially larger and almost doubles the estimate provided by Column (1). In addition, its significance has dropped to the

\footnotetext{
${ }^{10}$ The first stage estimation uses the linear probability model for the shock dummy and estimates the village fixed effects instead of the household fixed effects because the three instruments are all measures at the community level.
} 
$10 \%$ significance level. This raises the question as to whether our instruments are adequate. To answer this question, we check the first-stage regression results. First, both instruments have highly significantly positive coefficients, agreeing with our earlier conjectures. Second, the F-statistic is $\mathbf{5 1 . 3}$ when only the two instruments are included in the first-stage regression. So the problem of weak instruments is unlikely to exist. Third, we compare the $\mathrm{R}^{2}$ of the first-stage regression with the control variables in (15) and that without, and find that they are virtually the same: the former is 0.191 and the latter is 0.189 . So the two instruments provide most of the explanatory power for the incidence of major health shocks. The likely suspect for the large estimate in Column (4) is the group effects associated with the two instruments as both are community-level variables. In effect, the estimate for the shock dummy provided by Column (4) reflects the average effect between villages with more households hit by health shocks and those with less. This is of course not an ideal measure, but is the best that we can get with available data. No matter how crude it may be, the confirmation of a health shock's negative impact by the two-stage estimation still provides us confidence in our baseline estimation.

\subsection{Dynamic effects of health shocks}

Our data allows us to test Hypothesis 1 by studying the dynamic impacts of health shocks over a long period of 15 years after a shock happens. To that end, we estimate a variant of equation (15) by replacing the health shock dummy by 16 dummies indicating, respectively, the year when a shock happened, one year after the shock, ..., 
and fifteen years after the shock. Instead of presenting the whole set of results, we present the estimates for the dummies in Figure 6. The proof of Hypothesis 1 is evident because the negative impacts of a health shock clearly exhibit a U-shaped curve as time goes by. The estimates for the last three years are highly insignificant because of the small numbers of observations for those years. All the other years have significant estimates. At the trough of the U curve, which occurs in the eighth year after a sock, a health shock reduces per-capita income by $28.4 \%$. Using the average speed of recovery between the eighth and the fifteenth year, a shock-hit household is projected to be able to fully recover from the poverty trap after 10 more years. In total, a household with a major health shock would have to suffer a lower income for 19 years before fully recovery. This is a long time period by any means.

[Figure 6 about here]

\section{The Role of Village Elections}

China began to experiment village elections in 1987 (O’brien and Li, 2000). The 48 villages in our sample began the first election in various years. Figure 7 shows the number and accumulative percentage of villages that began elections in each year. Twelve of the sample villages were among the first in the nation to introduce elections in 1987. By 1990, more than half of the sample villages had at least one election. Two other features not shown in Figure 7 are relevant for our econometric estimations. One is that there is a clear regional pattern in the introduction of the first election. Villages in the same province tended to introduce the first election around the time when the 
province enacted an implementation version of the OLVC. The other is that the introduction of the first election was not related to the level of income. For example, villages in both Zhejiang (an affluent province) and Sichuan (a poorer province) began to have elections in 1987 whereas villages in Guangdong province (an affluent province) only began elections in 1998. These two features show that the introduction of the first election was independent of income but more dependent on the decision of the province. Nevertheless, this does not mean that the introduction of elections is totally exogenous to the village. The division of interests within the village may affect the timing of the introduction.

[Figure 7 about here]

As long as election is introduced, a village is required to hold elections every three years. Our primary concern is the introduction of the first election as it marks the start of grassroots democracy in a village. We thus create the election dummy that assigns value 1 for a village after it has introduced election and value 0 for a village before it introduced election or a village that has never introduced election.

\subsection{Elections and healthcare plans}

To test Hypothesis 2, we study whether a village had any healthcare plan. There are several kinds of healthcare plans in rural China. The most fundamental one is the village-based rural cooperative healthcare system. It was almost universal during the commune period, but was dismantled in most villages since the rural reform took place as its finance depended on the commune system. In some advanced regions, the 
village-based system has been replaced by the township-based system that provides limited reimbursements to clinic visits. In recent years, the central government has begun to promote a new sort of cooperative healthcare plan that is based on voluntary participation and pools at the county level. On top of those plans, some villages have also joined limited commercial healthcare plans. In our study, we code a village as having a healthcare plan as long as it had any of the above plans regardless of the benefits that they provided. We have data for 48 villages for the period of 1986 to 2002. Among those 48 villages, twenty-eight did not have any healthcare plan while four had a healthcare plan over the entire period. The rest of villages had a healthcare plan in part of years in the sample period. Among those villages, three had a plan before they started village elections and continued till 2002, while four started healthcare plans before elections but stopped (two of them) or had a period of interruption (two of them). The rest of the nine villages began to have a plan after or in the year when they held the first election. These raw data show that there was a large chance that healthcare plans were established after the first election was held.

We then estimate the following model with village and year fixed effects:

(16) $I_{j t}=Z_{j t} \beta+\alpha_{E} E_{j t}+\alpha_{j}+\alpha_{t}+e_{j t}$,

where $I_{j t}$ is a dummy variable indicating whether the $j$ th village had a healthcare plan in year $t, Z_{j t}$ is a set of control variables at the village level, $E_{j t}$ is a dummy variable indicating whether the $j$ th village had had at least one election in year $t, \alpha_{j}$ is the village specific effect for the $j$ th village, $\alpha_{t}$ is the year fixed effect for year $t$, and $e_{j t}$ is an i.i.d. error term. We have included in $Z_{j t}$ three variables, village average per-capita 
income (in $2002 \mathrm{RMB}$ ), the logarithm of village population, and the Gini coefficient of per-capita household income. The Gini coefficient is calculated using the original NFS household sample instead of the sample surveyed under this study. We do this because the original NFS sample covers 50-100 households in each village but 2003 supplemental survey had a much smaller sample because of our construction of the panel structure. It is natural to expect that villages with higher levels of income would be more likely to have a healthcare plan. A larger population increases the difficulty for collective decision, and higher Gini coefficient implies a more divided population, so both could reduce the chances for a village to set up a healthcare plan. Descriptive statistics of the control variables and the healthcare and election dummies can be found in Table 1.

The village fixed effects in equation (16) can effectively deal with the simultaneity between elections and healthcare plans arising from time-invariant village characteristics. In the meantime, the year fixed effects provide control on temporal shocks that are common to all the villages, including national policy changes regarding the election. However, there may still be simultaneities that the two sets of fixed effects cannot capture. To check our results, we will also estimate a two-stage version of equation (16) by instrumenting the election dummy with three variables: a dummy variable indicating when a province adopted the OLVC (i.e., it is equal to 1 if a province had adopted the law and equal to 0 otherwise), the number of surnames in the village, and the percentage of population of the largest surname. The last two variables do not have variations over time. To fit into the panel estimation, they are 
interacted with the first variable. The reason for using the timing of a province's adoption of the OLVC is evident against our earlier description on the introduction of the first election. The number of surnames is an indication for the degree of fraction in a village. A more fractioned village could be either less or more likely to start elections. On the one hand, politics in a more fractioned village is more contesting so elections are in a larger demand; on the other hand, though, it can be harder for a more fractioned village even to organize the first election.

The model in (16) is first estimated by the probit and the linear probability model (LMP) with village and year fixed effects. ${ }^{11}$ Except one village that began to have data since 1996, all the other 47 villages have 17 years of observations. This enables us to avoid the problem of a short panel that the probit estimates are inconsistent when fixed effects are estimated. The total number of observations is 806 .

[Table 3 about here]

The results of the two estimations are presented in the first two columns of Table 3. Marginal effects are reported for the probit model. The two-stage estimation is based on the linear probability model (LPM) and its results are presented in column 3 of the table. The first-stage regression yields an $\mathrm{R}^{2}$ of 0.67 and an F-statistic of 25.9 when only the three instruments are included, which are virtually the same as those when the second-stage variables are added. In addition, the introduction of elections to a village is strongly linked with a province's adoption of the election law (which

\footnotetext{
${ }^{11}$ The probit panel model is estimated using the routine provided by LIMDEP. This routine can only handle one-way fixed effects. The year fixed effects are thus estimated by manually adding year dummies in the regression.
} 
increases a village's chances to start elections by 32\%), but negatively related to the number of surnames in a village (although the effect is only $0.3 \%$ for one more surname). Therefore, our instruments are reasonable.

None of the three control variables except village average income in the two LPM models is significant. The probit model shows that elections significantly increase the chances of a village to set up a healthcare plan by $11.9 \%$. There is a possibility that this large effect is spurious, though. There are seven villages that began to have healthcare plans before they held any election, so the positive effect of election may only reflect the persistence of the healthcare plans. While this may be indeed a valid argument, there is also a probability that a village would have stopped its healthcare plans had there not been an election. Indeed, among the seven villages that began healthcare plans before their elections, two stopped healthcare plans before 2002, and two had several years of interruption. On the other hand, none of the nine villages that began their healthcare plans in or after the year of the first election had an interruption. However, the LPM does provide a much smaller estimate of $5.6 \%$ that has a reduced statistical significance, and the two-stage estimation turns the estimate insignificant. This shows that the positive effect of elections comes from the simultaneous determination between the first election and the establishment of a healthcare plan in a village.

\subsection{Elections and individual borrowings}

To test Hypothesis 3, we study the propensity of shock-hit families to borrow. 
There were 500 households that had at least one family member having a major illness in the period of 1987-2002. While the majority (73.6\%) had only one incidence of a major shock, $19.8 \%$ of them had two, $4.6 \%$ three, and $2 \%$ four or more. The total number of shocks was 676 . Among them, $35.8 \%$ had borrowed from informal sources (relatives, friends, or other people in the village). Informal sources are our major concern as our theoretical model predicts that election reduces individual borrowings from those sources. ${ }^{12}$ We will study the borrowing decision of the 676 cases of shocks. For that purpose, we define a binary choice variable describing whether a shock-hit family borrowed from an informal source to pay for the treatment of its sick member, and estimate a model defined by

$$
B_{j i k}=X_{j i k} \beta_{1}+X_{j i} \beta_{2}+X_{j} \beta_{3}+\alpha_{E} E_{j}+\alpha_{t}+e_{j i k}
$$

In the equation, $B_{j i k}$ is the borrowing decision ( $1=$ to borrow, $0=$ not to borrow) of household $i$ in the $j$ th village for its $k$ th shock. $X_{j i k}$ is a set of variables describing the sick person's characteristics in the year when he/she was sick. It includes his/her age, gender $($ male $=1$, female $=0$ ), and schooling years. Those variables are meant to control family preferences toward individual members. $X_{j i}$ is a set of household-level variables describing the household's characteristics in the year when the specific shock happened. It includes all the control variables used in equation (15) plus the per-capita value of the stock of physical assets in the year before the shock. This last variable is added to reflect Result 1 in the theoretical model. $X_{j}$ is a set of village-level

\footnotetext{
12 There were only a small number of illnesses, $2.1 \%$ of the 676 cases, for which families borrowed from official sources (mainly the rural credit cooperatives). So we ignore them in our analysis.
} 
variables for community characteristics in the year when the specific shock happened. It includes the three control variables that we used in equation (16) and the number of hospitals in the township and in the county, respectively. The first three variables are included to control things that are correlated with elections, and the last two are included to control the availability of healthcare. As we argued when we estimated equation (15), more hospitals in the nearby region lower the relative costs of treatments and induce a household to spend more on treatments. As a result, households living in a region with more hospitals would borrow more. $E_{j}$ is a dummy variable indicating whether the $j$ th village had held at least one election by the year when the specific shock happened. Finally, $\alpha_{t}$ is the year specific effect for the year when the specific shock happened, and $e_{j i k}$ is an i.i.d. error term.

[Table 4 about here]

The model in (17) is first estimated by the probit model. The results are presented in the first column of Table 4. Elections are shown not to significantly reduce the probability of a household to borrow. To further explore the issue, we take the sub-sample of shocks that only involved working adults, i.e., adults between 16 and 60 years old. A health shock on a working adult has a more significant impact on a family's income capability than a shock on a child or an old person, so elections could have a larger effect than before. We run both the probit and the LPM on this sub-sample (491 observations). Their results are presented in columns 2 and 3 of Table 4. The effect of elections has indeed increased reaching $16.7 \%$ and $14.9 \%$ in the probit and the LPM, respectively. The last column presents results of the two-stage 
estimation based on the sub-sample. The estimate for the effect of elections is comparable with the two previous estimates.

The estimates for several control variables are worth discussions. An older family (i.e., a family with a larger average age) tends less likely to borrow although the effect is very small. Consistent with our expectation, a larger stock of assets reduces a family's probability to borrow, but again, the effect is very small. The puzzling result is that per-capita land increases the probability to borrow. Perhaps the amount of land reflects more that the household resides in an agricultural region and thus is poor than that it has more assets. Among the village variables, the effect of per-capita income is significant but the magnitude is rather small. The interesting result is that the number of hospitals in the county significantly increases the probability to borrow, confirming our conjecture that more hospitals reduce the costs of treatment.

\subsection{Elections and long-term income}

To test Hypothesis 4, we add to the income equation (15) the election dummy defined in equation (16) and its interaction term with the shock dummy and estimate the modified model again. The first column of Table 5 presents the results for the shock and election dummies as well as their interaction term (the results of the control variables are not shown). The coefficients of all the three variables are highly significant and have the expected signs. By the results, a household living in a village without any election would lose $20.7 \%$ of its income due to a health shock; elections reduce this negative effect by 11.8 percentage points (or $56.5 \%$ of it), so a household 
living in a village with at least one election only loses $8.9 \%$ of its income. The election itself increases per-capita income by $29.7 \%$. However, this large effect may pick up some of the trend of income growth although we have controlled the year fixed effects.

[Table 5 about here]

The second column of Table 5 presents the results of the two-stage panel estimation that treats health shocks as endogenous using the same instruments used in R4 of Table 2. The negative effect of a health shock in a village without any election is substantially larger than what we have obtained in the plain panel estimation, but the effect of an election to mitigate it also becomes much larger. In relative terms, though, the election's effect does not change dramatically: now it is $51.8 \%$ of the negative effect of the health shock, which is close to the figure of $56.5 \%$ that we obtained in the plain panel estimation. As we discussed before, the estimated effect of a health shock when the shock is treated as endogenous is the shock's average effect across villages because both instruments are community-level variables. So a certain degree of noises exists in the estimates.

The third column of Table 5 reports the results treating the election dummy as endogenous but leaving health shocks exogenous. They are comparable with those of the plain panel estimation. In particular, the relative contribution of elections is now $52.8 \%$ of the total impact of health shocks. In addition, the direct contribution of elections to income growth now has been reduced to a more modest figure of $17.4 \%$. 


\section{Conclusions}

Using a longitudinal sample of households in 48 Chinese villages for the period of 1986-2002, this paper finds that a major health shock has strong and persistent negative impacts on household per-capita income. In the first 16 years starting with the year of the shock, a shock-hit household drops below its normal income trajectory by an average of $11.8 \%$. Using the estimates we obtained in our regressions, we predict that the negative impact of a major health shock would persist for a total of 19 years. To our knowledge, our study provides the first systematic assessment on health shocks' persistent impacts on rural households' income capabilities in developing economies.

Consistent with our theoretical predictions, we also find strong evidence that grassroots democracy helps alleviate the negative impacts of health shocks. Villages are found to be more likely to set up a healthcare plan after it has started elections. Families are less likely to borrow from informal sources to treat their sick working members if their village has begun elections. The contribution of elections is to reduce the chances to borrow by $16.7 \%$. As a result, village elections reduce the negative impact of a health shock on per-capita income by an average of 56.6\%. We attribute these findings to village elections' role in holding the village government accountable to the villagers. A health shock received by a poor household has a negative externality on the richer portion of the population, so a pro-poor policy can win supports from both the poor and the rich. 
Our findings make a tangible contribution to the literature of social capital and grassroots governance. Social capital has been emphasized in recent development literature as a device for rural people to effectively deal with income and other shocks. While our findings do not refuse this line of reasoning, we nevertheless show that public intervention can be an effective substitute for private social networks. Because relying on private social networks implies negative externalities on the whole population, public intervention has an advantage.

Although our theoretical model predicts that a healthcare plan can emerge even when it is fully self-financed, we would like to emphasize that a publicly subsidized plan is also possible to emerge in villages with elections. This is so because funds can be made available by better local governance instead of by raising taxes. Using the same dataset that this paper uses, Wang and Yao (2006) find that village elections have raised the share of public investment and reduced the share of administrative costs in village expenditures. They also find that elections have not increased the level of taxation in the village. Zhang et al. (2004) find similar results using data from Jiangsu province. Our econometric analysis did not distinguish between self-financed and publicly subsidized healthcare plans. Weighing against the above two studies, we are confident that the positive role of village elections in mitigating health shocks is not necessarily brought about by an expanding village government, but rather by better village governance.

Our findings also have strong implications to the debate on the Chinese experiment of village elections. While the initial intention of the experiment was to curb local 
corruption by empowering local people (O’Brien and Li, 2000), many have placed doubts on its effectiveness in achieving the goal. Our results provide strong evidence to support the positive role that the village election has played in the last 20 some years. Although there are still ample room for improvements and even mistakes to correct, village elections have shown its role to increase local accountability and for that matter, to contribute to poverty alleviation. 


\section{Appendix I: Derivation of the BGP for a shock-free farmer}

The Euler equations for the planning problem in (3) are:

$$
\begin{aligned}
& \text { (A1) } \frac{c_{t+1}}{c_{t}}=\rho\left[\alpha A\left(\frac{K_{t+1}}{K_{t}}\right)^{\alpha-1}+1-\delta\right] \\
& \text { (A2) } \frac{c_{t+1}}{c_{t}}=\rho h\left[(1-\alpha) A\left(\frac{K_{t+1}}{K_{t}}\right)^{\alpha}+\frac{1-\sigma}{h}\right]
\end{aligned}
$$

And the budget constraint is

(A3) $\mathrm{C}_{t}+K_{t+1}-(1-\delta) K_{t}+\frac{H_{t+1}}{h}-\frac{(1-\sigma)}{h} H_{t}=A K_{t}^{\alpha} H_{t}^{1-\alpha}$

At the BGP, let $\frac{c_{t+1}}{c_{t}}=\theta, \frac{K_{t+1}}{H_{t+1}}=M$, then from (A1) - (A3) we have

$$
\left[\frac{\frac{\theta}{\rho}-(1-\delta)}{\alpha A}\right]^{\frac{1}{\alpha-1}}=\left[\frac{\frac{\theta}{\rho h}-\frac{(1-\sigma)}{h}}{(1-\alpha) A}\right]^{\frac{1}{\alpha}}
$$

(A5) $\alpha A M^{\alpha-1}+1-\delta=h(1-\alpha) A M^{\alpha}+1-\sigma$

These two equations uniquely determine the values of $M$ and $\theta$. They are independent of the initial stocks of assets and health.

If $\delta=\sigma$, that is, assets and health have the same depreciation rates, we can get an explicit solution to $M$ and $\theta$. From (A4) and (A5), we get

(A6) $\theta=\rho\left[(1-\alpha)^{1-\alpha} \alpha^{\alpha} h^{1-\alpha} A+1-\delta\right]$, and

(A7) $\quad M=\frac{\alpha}{(1-\alpha) h}$.

Then it is easy to show that $\frac{y_{t+1}}{y_{t}}=\frac{C_{t+1}}{C_{t}}=\theta$, so income grows at a constant rate of $\theta$ -1 , which is also the growth rate for assets and health. 


\section{Appendix II: Proof of result 1}

Using the two constraints in (11) one can express $K_{E}$ and $B$ as a function of $\tilde{K}_{\tau}$ so the problem in (11) is reduced to a problem with one unknown $\widetilde{K}_{\tau}$, and the first-order condition is

(A8) $\frac{\partial V_{\tau}}{\partial B}+\frac{\partial V_{\tau}}{\partial \widetilde{K}_{\tau}}=0$

Using the implicit function theorem one gets

(A9) $\frac{\partial \tilde{K}_{\tau}}{\partial K_{\tau}}=\left(\frac{\partial^{2} V_{\tau}}{\partial B^{2}}+\frac{\partial^{2} V_{\tau}}{\partial \tilde{K}_{\tau} \partial B}\right) / \frac{d^{2} V_{\tau}}{d \tilde{K}_{\tau}^{2}}$,

where the denominator is negative because of the second-order condition. Then $\partial^{2} V_{\tau} / \partial B^{2}=\sum_{t=\tau}^{t=\tau+T-1}\left(\rho^{t-\tau} / c_{t}^{2}\right)\left(\partial c_{t} / \partial B\right)$ is negative, but $\partial^{2} V_{\tau} / \partial B \partial \tilde{K}_{\tau}=\sum_{t=\tau}^{t=\tau+T-1}\left(\rho^{t-\tau} / c_{t}^{2}\right)\left(\partial c_{t} / \partial \tilde{K}_{\tau}\right)$ is positive, so $\partial \tilde{K}_{\tau} / \partial K_{\tau}$ cannot be signed. But expressing $B$ and $\widetilde{K}_{\tau}$ as a function of $K_{E}$ and solve the problem in (11) again, it is easy to find that the sign of $\partial K_{E} / \partial K_{\tau}$ also depends on $\partial^{2} V_{\tau} / \partial B^{2}+\partial^{2} V_{\tau} / \partial B \partial \tilde{K}_{\tau}$ so $\partial \tilde{K}_{\tau} / \partial K_{\tau}$ and $\partial K_{E} / \partial K_{\tau}$ have the same sign. Since the sum of $\tilde{K}_{\tau}$ and $K_{E}$ is $K_{\tau}$, it is impossible that both decrease in $K_{\tau}$, so they both have to increase in $K_{\tau}$. As a result, a farmer with a larger stock of assets tends to borrow less. 


\section{References}

Becker, Gary, Kevin Murphy, and Robert Tamura (1990). "Human Capital, Fertility, and Economic Growth.” Journal of Political Economy, Vol. 98, No.5, Part 2: S12-S37.

Chattopadhyay, Raghabendra and Esther Duflo (2004). “Women as Policy Makers: Evidence from a Randomized Policy Experiment in India.” Econometrica, 72(5): 1409-43.

Foster, Andrew (1995). "Nutrition and Health Investment.” The American Economic Review, 85(2): 148-152.

Foster, Andrew and Mark Rosenzweig (2001). “Democratization, Decentralization and the Distribution of Local Public Goods in a Poor Rural Economy.” Manuscript, Department of Economics, Brown University.

Jacoby, Hanan and Emmanuel Skoufias (1996). "Risk, Financial Markets, and Human Capital in a Developing Country.” The Review of Economic Studies, 64: 311-335.

Liu, Shouying, Michael Carter and Yang Yao (1998). "Dimensions and Diversity of Property Rights in Rural China: Dilemmas on the Road to Further Reform.” World Development, 26(10): 1789-1806.

NBS (National Bureau of Statistics) (2003). China Statistical Yearbook, Beijing: China Statistical Press.

O’Brien, Kevin and Lianjiang Li (2000). “Accommodating 'Democracy' in a One-party State: Introducing Village Elections in China.” China Quarterly, Issue 162, 465-489. 
Shen, Yan and Yang Yao (2006). “Grassroots Democracy and Income Distribution: Evidence from Village Election in China.” CCER Working Paper Series E2006005, China Center for Economic Research, Peking University.

Srivastava, Ravi, N.C. Saxena, and Sukhadeo Thorat (forthcoming). “Land Institutions, Policy and Reforms in India.” In Shenggen Fan and Peter Hazel, eds. The Dragon and the Elephant: A Comparative Study of Economic and Agricultural Reforms in China and India. Washington D.C.: The International Food Policy Research Institute.

Strauss, John and Duncan Thomas (1998). "Health, Nutrition and Economic Development.” Journal of Economic Literature, 36(2): 766-817.

Wang, Shuna and Yang Yao (2006). “Grassroots Democracy and Local Governance: Evidence from Rural China.” CCER Working Paper Series E2006001, China Center for Economic Research, Peking University.

Zhang, Xiaobo, Shenggen Fan, Linxiu Zhang, and Jikun Huang (2004). "Local Governance and Public Goods Provision in Rural China.” Journal of Public Economics, 88(12): 2857-2871. 
Table 1. Basic statistics of variables

\begin{tabular}{|c|c|c|c|c|}
\hline Variables & Mean & St. dev. & Min. & Max. \\
\hline \multicolumn{5}{|c|}{ Personal variables (based on 676 persons having received a health shock) } \\
\hline Age & 44.00 & 18.68 & 0.00 & 91.00 \\
\hline Gender & 0.44 & 0.50 & 0.00 & 1.00 \\
\hline Schooling years & 4.56 & 3.38 & 0.00 & 14.00 \\
\hline
\end{tabular}

Household variables (1,185 households for 1987-2002, 13,515 cases)

$\begin{array}{lcccc}\text { Health shock dummy } & 0.22 & 0.42 & 0.00 & 1.00 \\ \text { Household size } & 4.53 & 1.82 & 1.00 & 21.00 \\ \text { Average age of household members } & 32.22 & 9.63 & 8.20 & 82.50 \\ \text { Dependent ratio } & 0.40 & 0.22 & 0.00 & 1.00 \\ \text { Per-capita land (in } m u \text { ) } & 1.37 & 2.02 & 0.00 & 69.75 \\ \text { Years of schooling of household } & 5.85 & 2.77 & 0.00 & 15.00 \\ \text { head } & 7.24 & 24.37 & 0.00 & 771.64 \\ \text { Per-capita assets (1,000 RMB) } & 1.09 & 0.36 & 0.00 & 4.00 \\ \text { Number of hospitals in township }^{*} & 2.82 & 1.62 & 1.00 & 8.00 \\ \text { Number of hospitals in county }^{*} & & & & \end{array}$

Village variables (48 villages for 1986-2002, 806 cases)

$\begin{array}{lcccc}\text { Election dummy } & 0.66 & 0.47 & 0.00 & 1.00 \\ \text { Healthcare plan dummy } & 0.27 & 0.44 & 0.00 & 1.00 \\ \text { Average per-capita income (1,000 } & 7.55 & 14.76 & 0.37 & 119.78 \\ \text { RMB) } & 1458.27 & 1061.99 & 235.00 & 5247.00 \\ \text { Population } & 0.28 & 0.09 & 0.06 & 0.67 \\ \text { Gini coefficient }\end{array}$

Notes: All financial figures are converted into 2002 RMB using the consumer price index published in NBS (2003).

* The statistics of these two variables are calculated based on the household dataset. 
Table 2. Average effects of health shocks on income

\begin{tabular}{|c|c|c|c|c|}
\hline Variables & (1) & (2) & (3) & (4) \\
\hline \multirow[t]{2}{*}{ Constant } & $7.193^{* * *}$ & $7.405^{* * *}$ & $7.291^{* * *}$ & $7.084^{* * *}$ \\
\hline & $(0.275)$ & $(0.243)$ & $(0.273)$ & $(0.277)$ \\
\hline \multirow[t]{2}{*}{ Health shock dummy } & $-0.118^{* * *}$ & $-0.124^{* * *}$ & $-0.135^{* * *}$ & $-0.233^{*}$ \\
\hline & $(0.026)$ & $(0.027)$ & $(0.044)$ & $(0.140)$ \\
\hline \multirow[t]{2}{*}{ Household size } & $-0.032^{* * *}$ & & $-0.040^{* * *}$ & $-0.032^{* * *}$ \\
\hline & $(0.006)$ & & $(0.009)$ & $(0.006)$ \\
\hline \multirow[t]{2}{*}{ Average household age } & $0.033^{* * *}$ & & 0.011 & $0.040^{* * *}$ \\
\hline & $(0.006)$ & & $(0.009)$ & $(0.007)$ \\
\hline Average household age & $-0.436 \mathrm{E}-3^{* * *}$ & & $-0.114 \mathrm{E}-4$ & $-0.493 \mathrm{E}-3^{* * *}$ \\
\hline squared & $(0.811 \mathrm{E}-4)$ & & $(0.142 E-3)$ & $(0.859 \mathrm{E}-4)$ \\
\hline \multirow[t]{2}{*}{ Dependent ratio } & $-0.646^{* * *}$ & & $-0.603^{* * *}$ & $-0.660^{* * *}$ \\
\hline & $(0.039)$ & & $(0.061)$ & $(0.040)$ \\
\hline \multirow[t]{2}{*}{ Per-capita land $(m u)$} & $0.059^{* * *}$ & $0.075^{* * *}$ & $0.100^{* * * *}$ & $0.056^{* * *}$ \\
\hline & $(0.006)$ & $(0.006)$ & $(0.012)$ & $(0.006)$ \\
\hline \multirow[t]{2}{*}{ Years of schooling of hh head } & 0.021 & 0.011 & 0.017 & 0.021 \\
\hline & $(0.041)$ & $(0.042)$ & $(0.036)$ & $(0.041)$ \\
\hline Adjusted $\mathrm{R}^{2}$ & 0.422 & 0.403 & 0.501 & 0.421 \\
\hline Number of obs. & 13,515 & 13,515 & 7,290 & 13,515 \\
\hline
\end{tabular}

Notes: All four models are estimated by the two-way fixed-effect panel method. Column (1) uses the whole sample of 1,185 households of 48 villages in the period 1987-2002 and includes the control variables; Column (2) drops the demographic variables; Column (3) uses data for the period 1987-1996; and Column (4) instruments health shocks by the number of hospitals in the township/xiang and the number of hospitals in the county. Heteroscedasticity-corrected standard errors are reported in the parentheses.

* Significant at the $10 \%$ significance level; ** Significant at the $5 \%$ significance level; *** Significant at the $1 \%$ significance level. 
Table 3. Elections' impact on village healthcare plans ${ }^{1}$

\begin{tabular}{|c|c|c|c|}
\hline Variables & $\begin{array}{c}\text { Probit } \\
\text { panel estimation }^{2}\end{array}$ & $\begin{array}{c}\text { LPM } \\
\text { panel estimation }^{3}\end{array}$ & $\begin{array}{c}\text { Two-stage } \\
\text { panel estimation }^{4}\end{array}$ \\
\hline Constant & & $\begin{array}{c}0.167 \\
(0.762)\end{array}$ & $\begin{array}{l}-0.042 \\
(0.767)\end{array}$ \\
\hline Election dummy & $\begin{array}{l}0.116^{* * *} \\
(0.000)\end{array}$ & $\begin{array}{l}0.056^{*} \\
(0.031)\end{array}$ & $\begin{array}{c}0.063 \\
(0.058)\end{array}$ \\
\hline $\begin{array}{l}\text { Village average income } \\
(1,000 \mathrm{RMB})\end{array}$ & $\begin{array}{c}0.022 \\
(0.249)\end{array}$ & $\begin{array}{l}0.029^{* *} \\
(0.013)\end{array}$ & $\begin{array}{l}0.027^{* *} \\
(0.013)\end{array}$ \\
\hline ln(population) & $\begin{array}{c}0.674 \\
(8.152)\end{array}$ & $\begin{array}{c}0.047 \\
(0.109)\end{array}$ & $\begin{array}{c}0.029 \\
(0.110)\end{array}$ \\
\hline Gini coefficient & $\begin{array}{c}0.567 \\
(6.334)\end{array}$ & $\begin{array}{c}0.164 \\
(0.164)\end{array}$ & $\begin{array}{c}0.148 \\
(0.164)\end{array}$ \\
\hline $\begin{array}{l}\text { Log-likelihood } \\
\text { function/Adjusted R² }\end{array}$ & -104.62 & 0.712 & 0.711 \\
\hline
\end{tabular}

\section{Notes:}

1. The number of villages is 48 , and time span is 1986-2002. The number of observations is 806 . All three regressions are estimated with village and year fixed effects. * Significant at the $10 \%$ significance level; $* *$ Significant at the $5 \%$ significance level; $* * *$ Significant at the $1 \%$ significance level.

2. Marginal effects estimated at the means of the explanatory variables are reported. Robust standard errors of the marginal effects are reported in the parentheses. LIMDEP does not provide the constant term for its probit panel estimation.

3. Heteroscedasticity-corrected standard errors are reported in the parentheses.

4. The 2SLS panel estimation is based on the LPM model and uses the timing of provincial adoption of the election law and its interaction terms with the number of surnames and the percentage of the largest surname as the instruments for the election dummy. Heteroscedasticity-corrected standard errors are reported in the parentheses. 
Table 4. Impacts of elections on individual borrowings ${ }^{1}$

\begin{tabular}{|c|c|c|c|c|}
\hline Variables & Probit I $^{2}$ & ${\text { Probit } \mathrm{II}^{2}}^{2}$ & $\mathrm{LPM}^{3}$ & $2 \mathrm{SLS}^{4}$ \\
\hline \multirow{2}{*}{ Constant } & 0.026 & -0.359 & 0.248 & 0.160 \\
\hline & $(0.286)$ & $(0.357)$ & $(0.324)$ & $(0.308)$ \\
\hline \multirow{2}{*}{ Election dummy } & -0.008 & $-0.167^{* *}$ & $-0.149^{* *}$ & $-0.157^{*}$ \\
\hline & $(0.006)$ & $(0.083)$ & $(0.075)$ & $(0.092)$ \\
\hline \multicolumn{5}{|l|}{ Personal variables } \\
\hline \multirow{2}{*}{ Age } & -0.001 & $0.005^{* * *}$ & $0.004^{* *}$ & $0.004^{* *}$ \\
\hline & $(0.001)$ & $(0.002)$ & $(0.002)$ & $(0.002)$ \\
\hline \multirow{2}{*}{ Gender } & -0.041 & 0.015 & -0.019 & -0.015 \\
\hline & $(0.039)$ & $(0.048)$ & $(0.044)$ & $(0.044)$ \\
\hline \multirow{2}{*}{ Schooling years } & 0.001 & -0.003 & -0.003 & -0.002 \\
\hline & $(0.006)$ & $(0.008)$ & $(0.007)$ & $(0.007)$ \\
\hline \multicolumn{5}{|l|}{ Household variables } \\
\hline \multirow{2}{*}{ Household size } & $-0.025^{* *}$ & 0.018 & 0.014 & 0.015 \\
\hline & $(0.012)$ & $(0.015)$ & $(0.014)$ & $(0.014)$ \\
\hline \multirow{2}{*}{ Average household age } & $-0.005^{*}$ & $-0.008^{* * *}$ & $-0.008^{* * *}$ & $-0.008^{* * *}$ \\
\hline & $(0.003)$ & $(0.003)$ & $(0.003)$ & $(0.003)$ \\
\hline \multirow{2}{*}{ Dependent ratio } & -0.022 & 0.075 & 0.082 & 0.008 \\
\hline & $(0.088)$ & $(0.120)$ & $(0.107)$ & $(0.107)$ \\
\hline \multirow{2}{*}{ Per-capita land (mu) } & $0.039^{* * *}$ & $0.037^{* * *}$ & $0.038^{* * *}$ & $0.039^{* * *}$ \\
\hline & $(0.011)$ & $(0.014)$ & $(0.012)$ & $(0.012)$ \\
\hline \multirow{2}{*}{ Per-capita assets (1,000 RMB) } & -0.001 & $-0.002^{* *}$ & $-0.001^{* * *}$ & $-0.001^{* * *}$ \\
\hline & $(0.001)$ & $(0.001)$ & $(0.000)$ & $(0.000)$ \\
\hline Years of schooling of & 0.006 & 0.008 & 0.007 & 0.005 \\
\hline household head & $(0.007)$ & $(0.009)$ & $(0.009)$ & $(0.009)$ \\
\hline \multicolumn{5}{|l|}{ Village variables } \\
\hline Average per-capita income & $-0.008^{* * *}$ & $-0.006^{* *}$ & $-0.005^{* * *}$ & $-0.005^{* * *}$ \\
\hline$(1,000 \mathrm{RMB})$ & $(0.003)$ & $(0.003)$ & $(0.002)$ & $(0.002)$ \\
\hline \multirow{2}{*}{$\ln ($ population) } & -0.035 & 0.004 & -0.003 & 0.005 \\
\hline & $(0.035)$ & $(0.042)$ & $(0.038)$ & $(0.037)$ \\
\hline \multirow{2}{*}{ Gini coefficient } & 0.132 & -0.030 & -0.046 & 0.010 \\
\hline & $(0.303)$ & $(0.353)$ & $(0.313)$ & $(0.308)$ \\
\hline \multirow{2}{*}{$\begin{array}{l}\text { Number of hospitals in } \\
\text { township/xiang }\end{array}$} & 0.047 & 0.044 & 0.041 & 0.038 \\
\hline & $(0.047)$ & $(0.054)$ & $(0.050)$ & $(0.050)$ \\
\hline \multirow{2}{*}{ Number of hospitals in county } & $0.021^{*}$ & $0.025^{*}$ & $0.022^{*}$ & $0.023^{*}$ \\
\hline & $(0.011)$ & $(0.014)$ & $(0.013)$ & $(0.013)$ \\
\hline Psudo-R ${ }^{2}$ /Adjusted $\mathrm{R}^{2}$ & 0.108 & 0.123 & 0.067 & 0.066 \\
\hline Number of cases & 676 & 491 & 491 & 491 \\
\hline
\end{tabular}

Notes:

1. All regressions are estimated with year fixed effects. * Significant at the $10 \%$ significance level; ** Significant at the 5\% significance level; *** Significant at the $1 \%$ significance level.

2. Both regressions are probit estimation on the decision whether to borrow from informal sources. Probit I uses the whole sample of shocks; probit II uses the sub-sample of shocks on 
family labors between 16 and 60 years old. Marginal effects estimated at the means of the explanatory variables. Robust standard errors of the marginal effects are reported in the parentheses.

3. The linear probit model is estimated with the sample of probit II. Heteroscedasticity-corrected standard errors are reported in the parentheses.

4. The 2SLS panel estimation is conducted with the LPM model using the sample of probit II. It uses the timing of provincial adoption of the election law and its interaction terms with the number of surnames and the percentage of the largest surname as the instruments for the election dummy. Heteroscedasticity-corrected standard errors are reported in the parentheses.

Table 5. Selected results for the effect of village elections on household income

\begin{tabular}{|c|c|c|c|}
\hline Variables & $\begin{array}{l}\text { Plain panel } \\
\text { estimation }\end{array}$ & $\begin{array}{l}\text { Two-stage panel } \\
\text { estimation for } \\
\text { health shocks }\end{array}$ & $\begin{array}{c}\text { Two-stage panel } \\
\text { estimation for } \\
\text { elections }\end{array}$ \\
\hline \multirow[t]{2}{*}{ Health shock dummy } & $-0.207^{* * *}$ & $-0.413^{* *}$ & $-0.231^{* * *}$ \\
\hline & $(0.048)$ & $(0.194)$ & $(0.059)$ \\
\hline \multirow[t]{2}{*}{ Election dummy } & $0.297^{* * *}$ & $0.319^{* * *}$ & $0.174^{* * *}$ \\
\hline & $(0.023)$ & $(0.036)$ & $(0.051)$ \\
\hline Shock dummy× & $0.111^{* * *}$ & $0.218^{*}$ & $0.122^{*}$ \\
\hline Election dummy & $(0.048)$ & $(0.127)$ & $(0.063)$ \\
\hline Adjusted $\mathrm{R}^{2}$ & 0.431 & 0.430 & 0.423 \\
\hline
\end{tabular}

Notes: The sample contains 1,185 households in 48 villages for the period 1987-2002, and the number of observations is 13,515. All three regressions are estimated with household and year fixed effects. Plain panel estimation treats both health shocks and elections as exogenous, and the other two regressions treat health shocks and elections as endogenous, respectively. The instruments are the same as those used before. Heteroscedasticity-corrected standard errors are presented in the parentheses. Results for the control variables are not shown.

* Significant at the $10 \%$ significance level; ** Significant at the $5 \%$ significance level; *** Significant at the $1 \%$ significance level. 
Figure 1. Simulated dynamics of a health shock

Chart A. Dynamics of the level of income

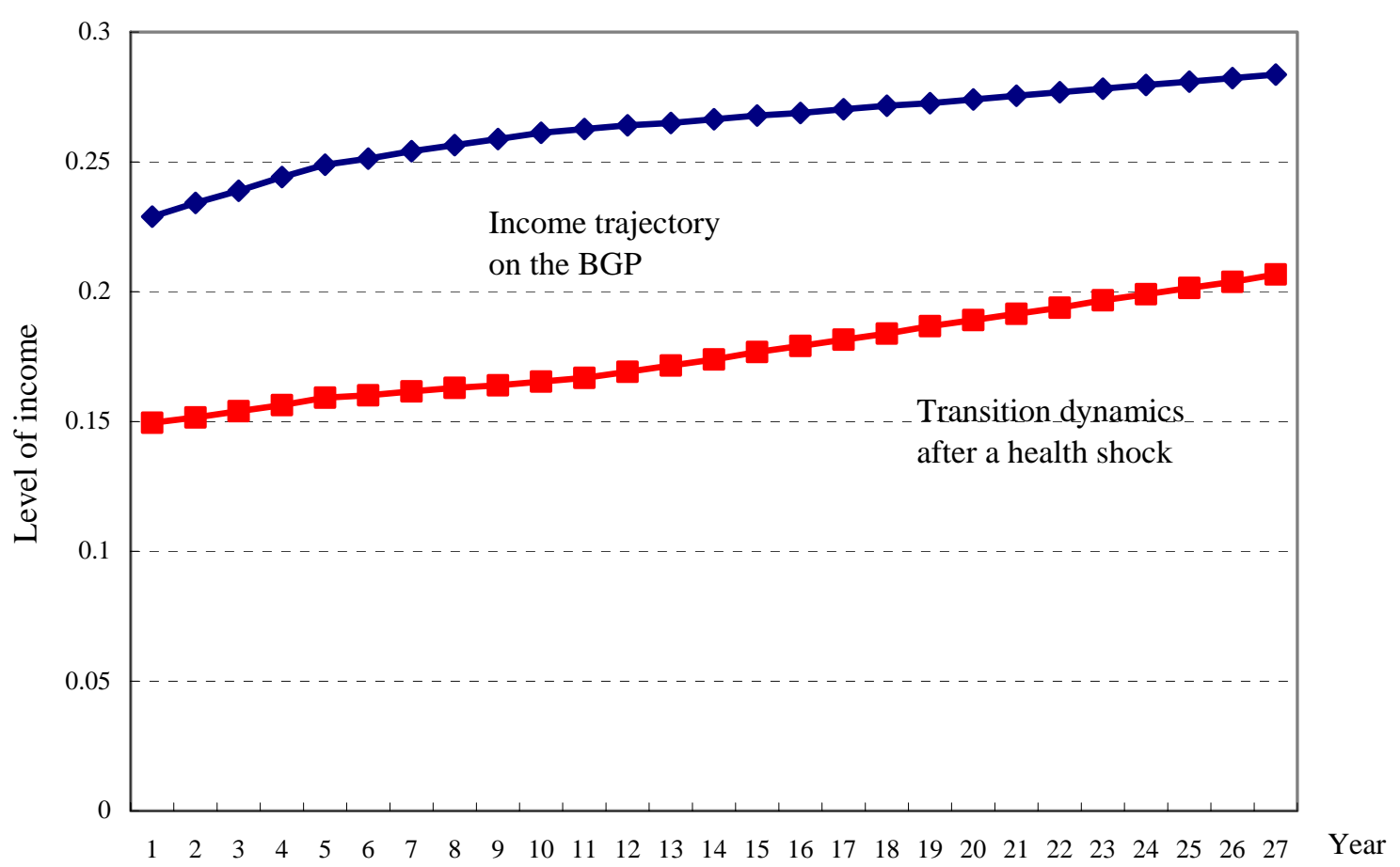

Chart B. Income drop after a health shock

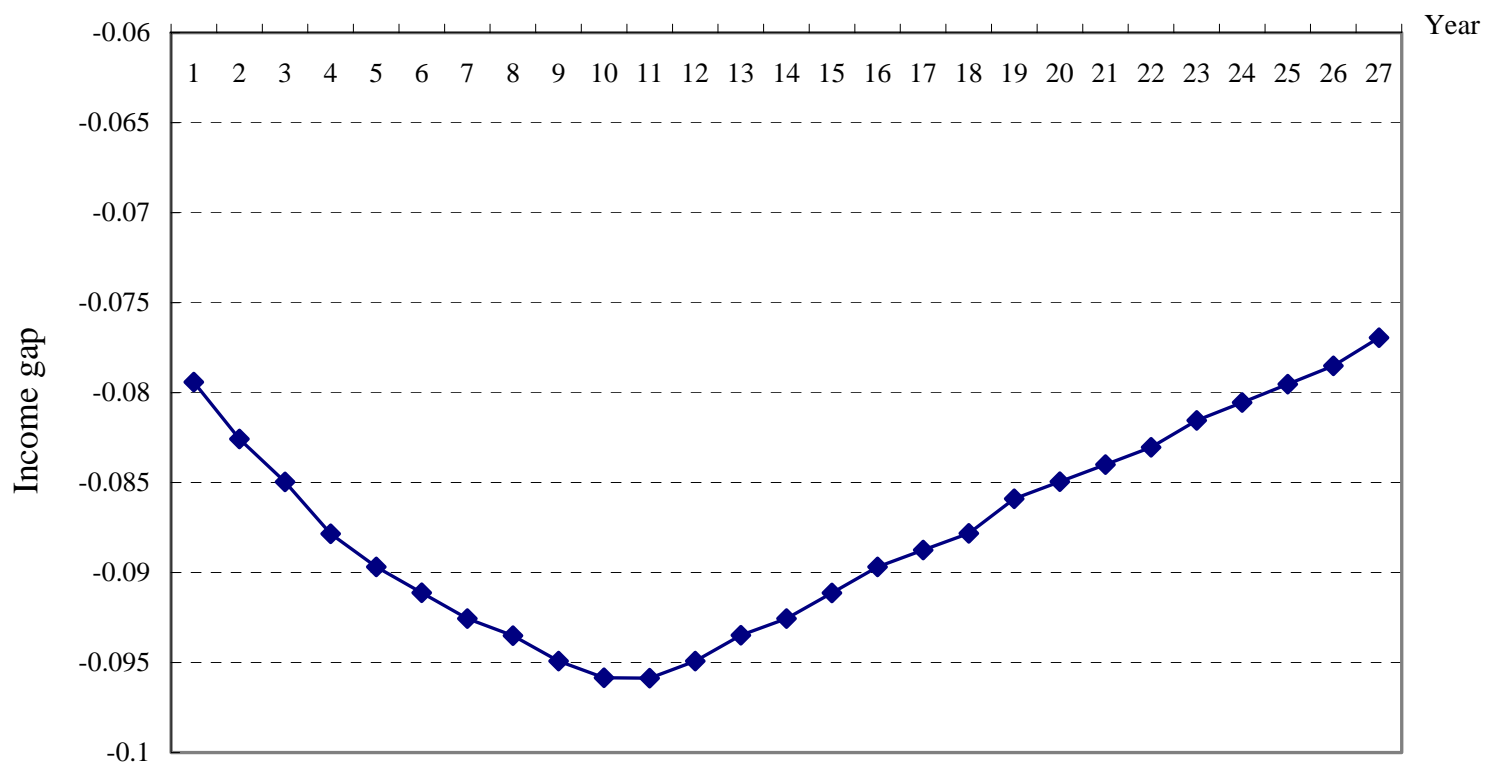

Notes: The parameters used in the simulation are: $A=0.3 ; \delta=0.05 ; \sigma=0.05 ; h=0.5 ; \rho=$ 0.95; $\alpha=0.3 ; r=0.05 ; T=5$. Initial asset and health stocks are obtained from the BGP and take the values of 0.60 and 0.85 , respectively. 
Figure 2. Voting and the insurance scheme

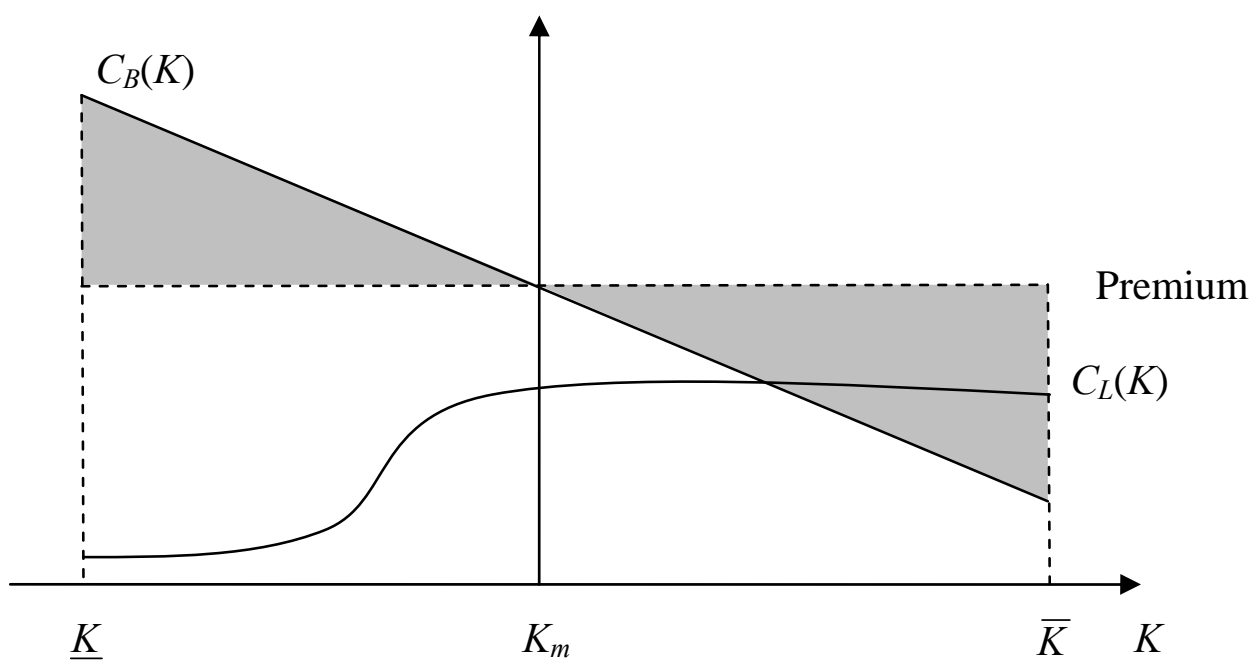

Figure 3. Income growth in the sample

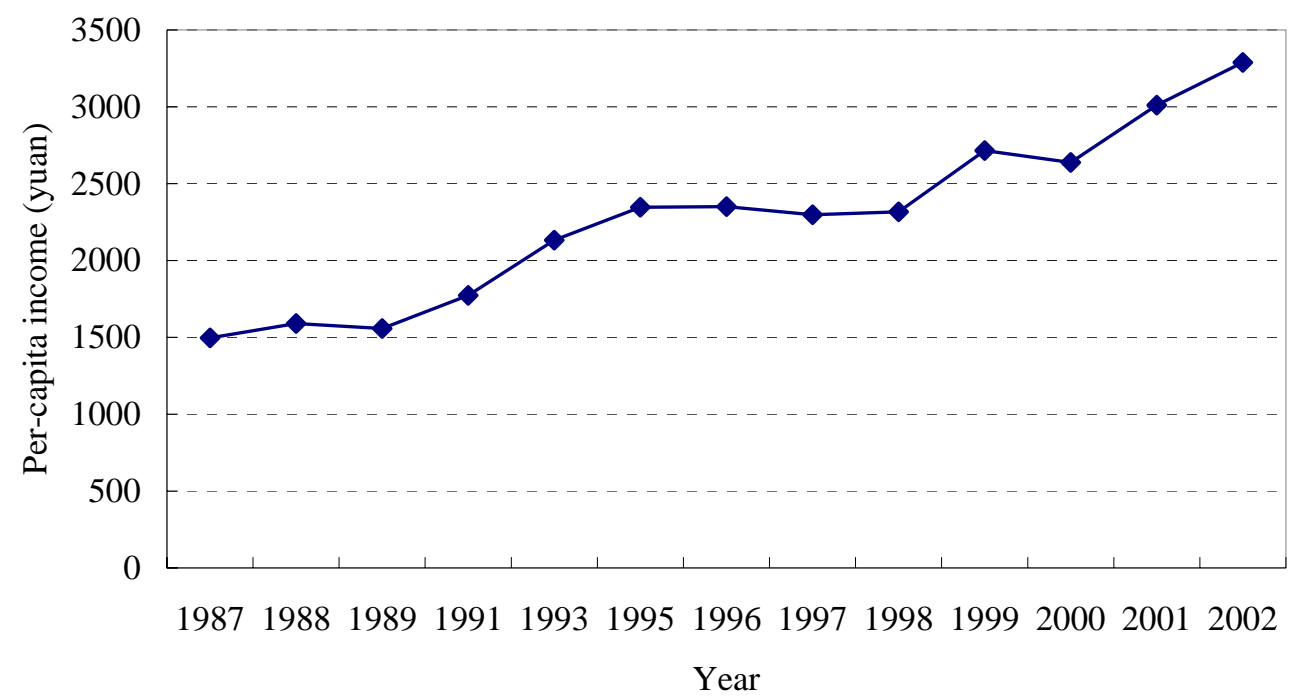

Notes: Income has been converted to 2002 RMB using the consumer price index published in NBS (2003). 
Figure 4. Income and incidence of health shocks

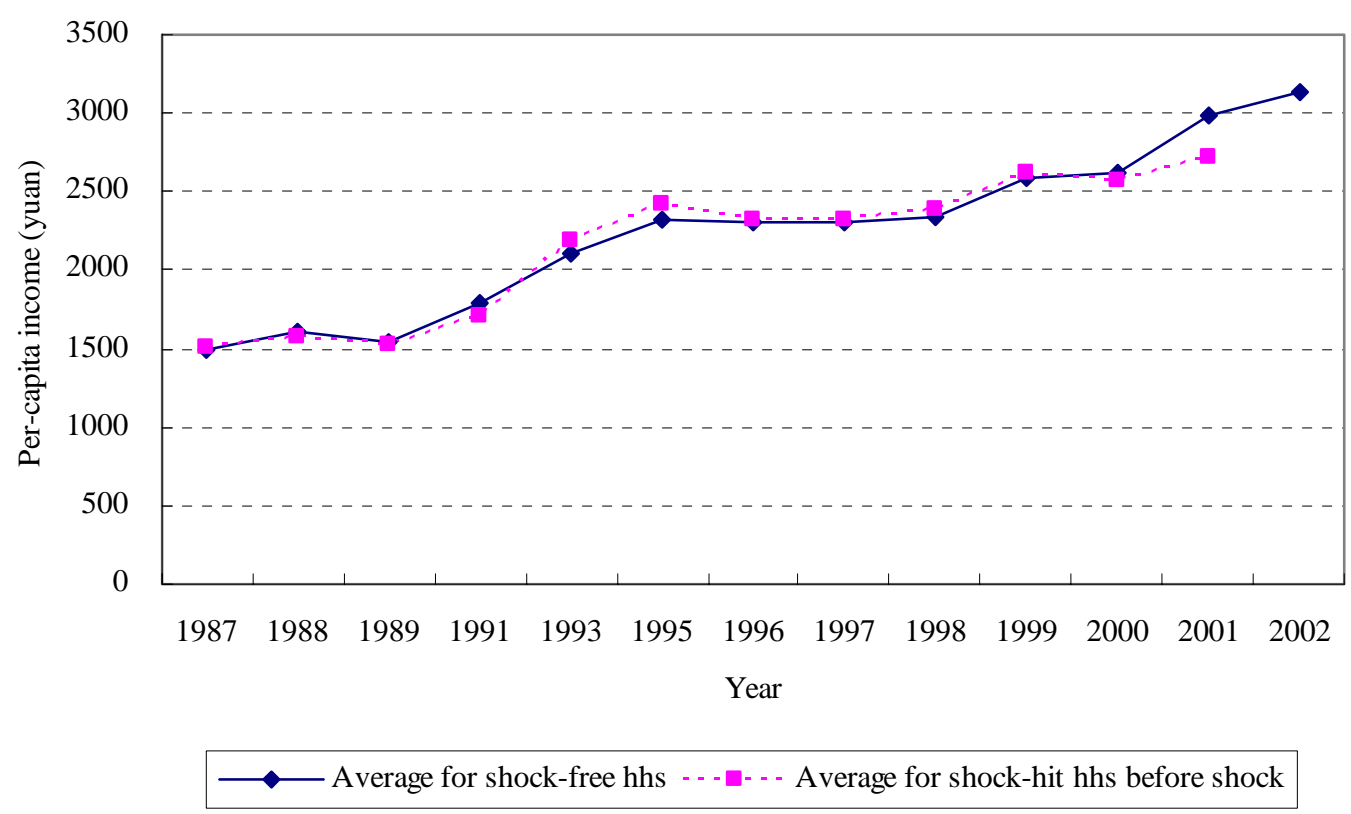

Notes: Income has been converted to 2002 RMB using the consumer price index published in NBS (2003). The two series represent, respectively, annual average income for households that were not hit by a major health shock in the entire period 1987-2002 and annual average income in the years before a major health shock came for households that were hit by a major health shock. A shock-hit household is defined as one that had at least one of its member being hit by a major health shock in the period 1987-2002.

Figure 5. Incidence of health shocks in the surveyed time period

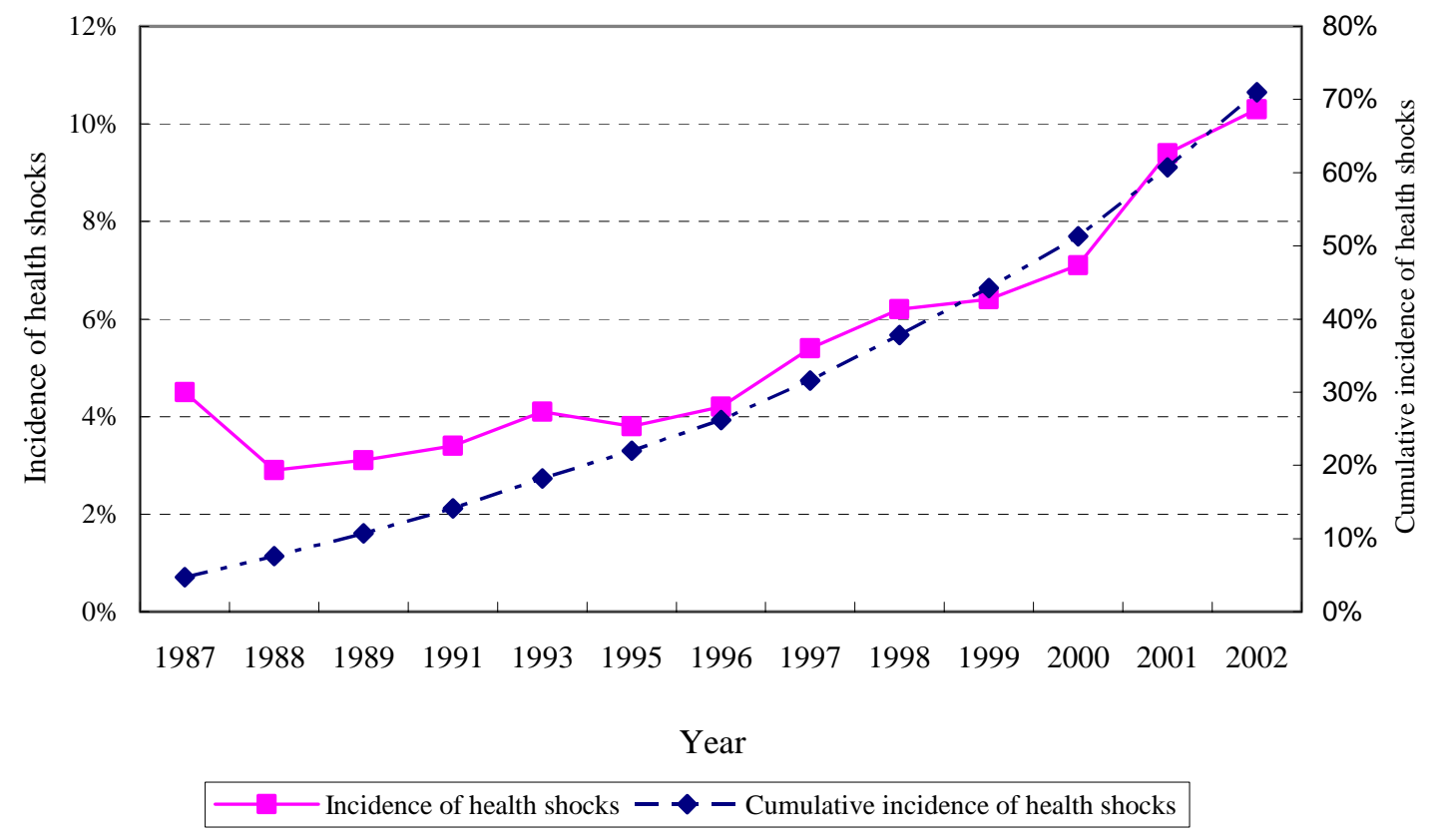


Figure 6. Dynamic effects of health shocks

Years after shock

$(0.01)(0.01)(0.01)(0.10)(0.08)(0.00)(0.07)(0.00)(0.00)(0.01)(0.00)(0.02)(0.01)(0.21)(0.36)(0.48)$

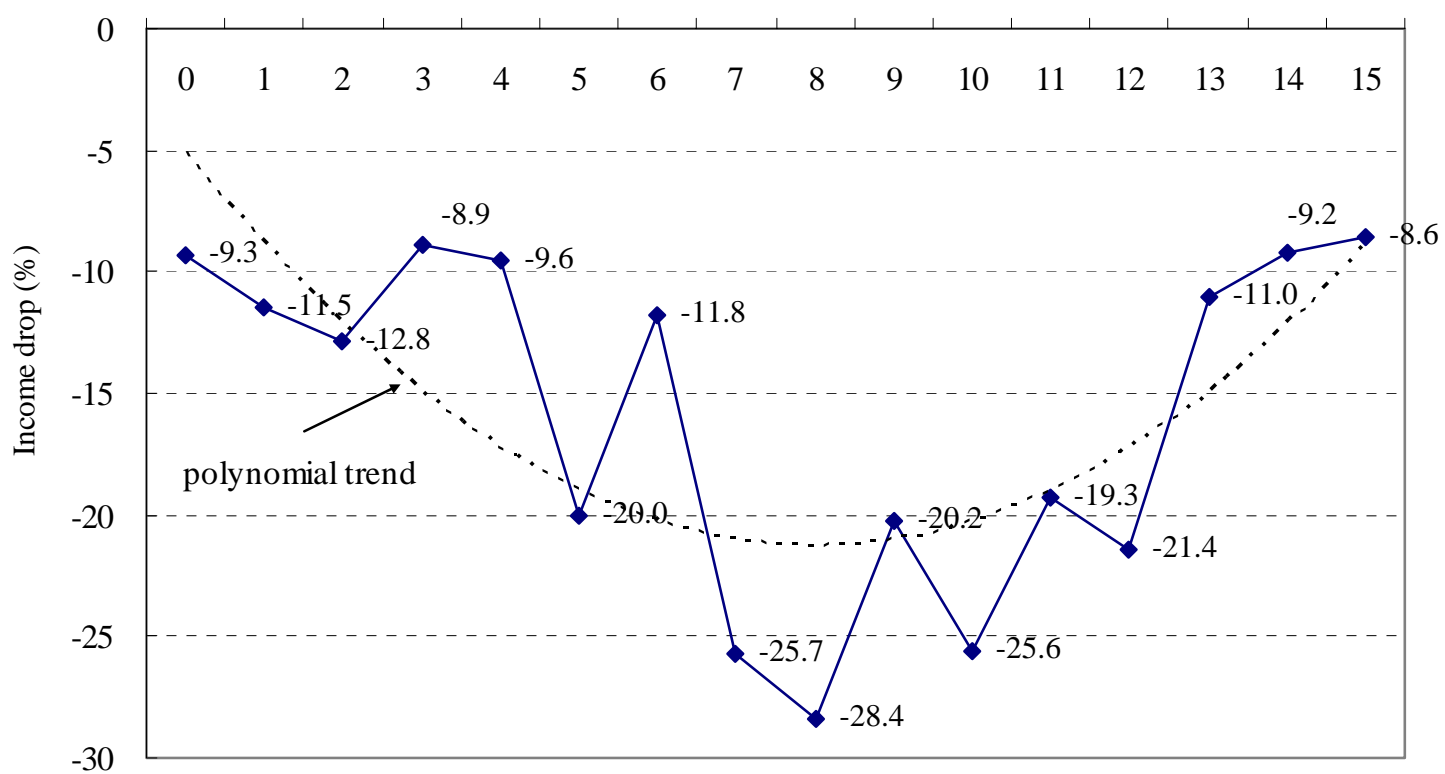

Notes: The curve is drawn based on the dynamic effects obtained from the estimation of equation (15) by replacing the health shock dummy with 16 dummies indicating the years after a shock. Figures in parentheses are significance levels of the estimates. 
Figure 7. Introduction of elections in sample villages

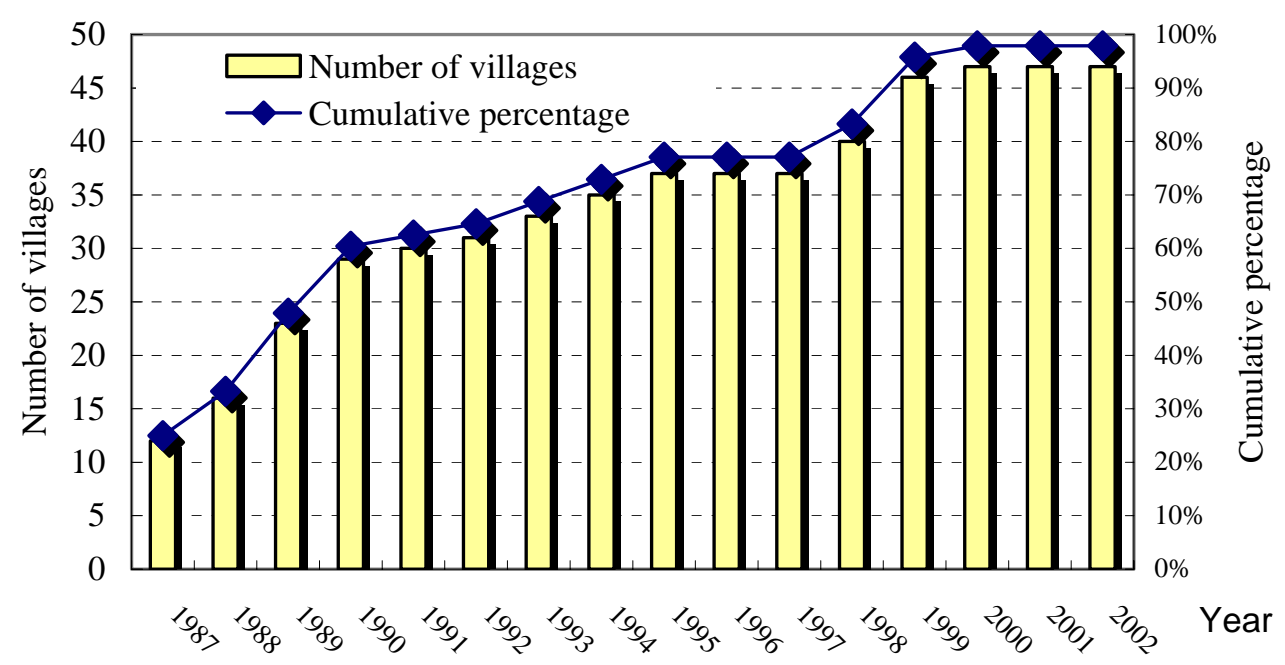

